\title{
Stansky's Monster: A Critical Examination of Fidelity Magellan's "Frankenfund"
}

\author{
by \\ Ross M. Miller \\ State University of New York (SUNY) at Albany \\ Department of Finance \\ Albany, NY 12222 \\ and \\ Miller Risk Advisors \\ 2255 Algonquin Road, Niskayuna, NY 12309-4711 \\ millerrm@alumni.caltech.edu \\ http://www.millerrisk.com
}

(518) 346-0781

First draft: February 2007

Current draft: February 2007

\begin{abstract}
Fidelity Magellan Fund has become the poster child of closet (or shadow) index funds. While the fund's tendency to mimic the S\&P 500 Stock Index first garnered attention in the early 1990s, this propensity turned extreme a decade later under the leadership of Robert Stansky. Employing analytic techniques developed in a recent article by the author, this article demonstrates that if the active component of Magellan were considered as a standalone market-neutral investment, its investors would have lost at least 50\% of their money between 2002 and 2004. The bulk of this loss, which is more than four times greater than the worst comparable hedge fund, cannot be accounted for by any combination of Magellan's stated expenses, portfolio turnover, investment style, industry selections, or stock picks. This article posits that computer models employed by Mr. Stansky to pit his fund directly against the S\&P 500 were a likely source of the unexplained losses.
\end{abstract}

\footnotetext{
* No external funding was used to conduct the research described in this article and this research was undertaken independently of any past, current, or pending actions against Fidelity by the State of New York or by the clients of Miller Risk Advisors. The author owns mutual funds managed by Fidelity and Vanguard.
} 


\section{Background}

In its heyday during the 1980s, the Fidelity Magellan Fund was the brightest star in the mutual fund galaxy. Its legendary manager, Peter Lynch, consistently beat the major indexes, turning the fund, which had long been overshadowed by Fidelity's flagship Trend Fund, into America's largest and most celebrated. Lynch attributed much of his success to a knack for picking "tenbagger" stocks. He claims to have discovered several tenbaggers, which got their name by increasing tenfold in value in a relatively short time, using methods that investors without Fidelity's research resources could emulate. In a few instances, Peter's did little more than ask his spouse Carolyn what caught her fancy at the supermarket and the next tenbagger was born.

Peter Lynch took an early retirement from portfolio management in 1989 while still at the top of his game and remained at Fidelity in a senior management role. The dominance that Lynch had established for Magellan would continue for several years. Of course, as the fund grew, the impact of each new tenbagger on the fund's performance was proportionately diminished. Bold steps were necessary in order for Magellan to remain on top in the growing and brutally competitive market for mutual funds.

Magellan received an infusion of new blood in 1992 when 33-year-old Jeffrey Vinik was tapped as its new portfolio manager. He adeptly managed Magellan's behemoth portfolio until 1996. Early that year he completed a major overhaul of the fund's portfolio that placed over a quarter of its assets in fixed income securities. This was a defensive measure taken at a time when the conventional wisdom held that the stock market had risen too far, too fast. The stock market continued to set all-time highs on an almost daily basis and Vinik's bad timing caused Magellan to trail its benchmark, the Standard \& Poor's 500 Stock Index (S\&P 500), by over 10\% for 1996.

Jeffrey Vinik's transgressions, however, affected more than the fund's relative performance. In an environment where investors were beginning to pay attention to style drift - the tendency for a fund to attempt to juice up its returns by deviating from its investment objective contained in its prospectus-Magellan had much more than drifted away from the growth stocks that it was supposed to be holding on behalf of its investors.

Five months into Magellan's annus horribilis of 1996, Jeffrey Vinik voluntarily left Fidelity altogether to launch what would become a flourishing hedge fund operation and was replaced by Robert Stansky, a seasoned Fidelity portfolio manager. He had started out at Fidelity as a research assistant to Peter Lynch and had moved up in the organization the old-fashioned way, by picking growth stocks.

Magellan was monstrously large before Robert Stansky took over, but it was a gentle giant whose behavior, if not always predictable, was at least comprehensible. Investors could gain some understand of how the fund worked by reading the bestsellers that Peter Lynch wrote chronicling his days there. Lynch wrote for the common investor and his books had a homey appeal that launched them to the top of the nonfiction bestseller lists. No equations were to be 
found among his trading chronicles; the only technical content was a smattering of hand-drafted charts with scrawled annotations from the master himself. Lynch's brief words about his student days at the Wharton School and the rigorous quantitative training he received there were anything but kind (Lynch, 1989, p. 34). Like Ned Johnson and Gerald Tsai before him at Fidelity, Lynch cooked up his portfolios containing only the freshest handpicked stocks. Mr. Stansky would transform Magellan into something altogether different, something unnatural.

\section{The Shortfall}

In the cinematic adaptations of Mary Shelly's classic horror novel, Dr. Victor Frankenstein pieces his monster together from body parts obtained from several corpses and reanimates it using the high technology of the early $19^{\text {th }}$ century, electricity. Things go badly for Frankenstein's creation and mayhem ensues.

Robert Stansky constructed Magellan's portfolio from holdings of 200 or more stocks. Over time, Magellan's portfolio became more than a collection of favored stocks, it had become a synergistic entity that took on a life of its own. Stansky had created what might best be termed a "frankenfund" that would ultimately destroy billions of dollars of its investor's wealth. ${ }^{1}$

Fortunately for Mr. Stansky, torch-wielding fund holders never ran him out of Boston. Magellan did, however, experience massive withdrawals and was ousted from many defined contribution plans, a major key to Fidelity's pre-eminence in the mutual fund industry.

Robert Stansky got off to a seemingly auspicious start at Magellan. In the process of liquidating the fixed income securities stockpiled by Jeff Vinik, Stansky boosted the fund's positions in growth stocks. ${ }^{2}$ He got aboard Magellan just in time to profit from the headiest days of the 1990s stock boom. The fund performed well for Stansky, although not as spectacularly as it did under Peter Lynch in similar boom times. More aggressive portfolio managers at other funds who stacked their portfolios with Internet stocks upstaged the more cautious Mr. Stansky.

The new century, however, was a different story. Beginning in 2000, Magellan moved in tandem with the S\&P 500 - exhibiting virtually identical movements to those of the index and generating parallel returns. In the wake of the Nasdaq crash, Stansky's timidity toward technology stocks worked to the benefit of Magellan's holders. Then, beginning in 2002, while the fund's pattern of volatility remained in line with that of the S\&P 500, its performance began to falter.

Figure 1 shows Magellan's returns return relative to the S\&P 500 (as represented by Vanguard Institutional Index Fund $)^{3}$ between 2002 and 2004, a period during which Magellan lagged the index by nearly $9 \%$. Although Magellan once had high front-end loads and management fees, by

\footnotetext{
${ }^{1}$ The earliest use of frankenfund appears to be attributable to financial columnist Andrew Allentuck (2000) who uses it to refer to a mutual fund that is "racking up consistently awful numbers."

${ }^{2}$ See Wyatt (1997) for a discussion of Magellan's transition from Vinik to Stansky.

${ }^{3}$ The Vanguard Institutional Index Fund provides a benchmark that is tradable on the same terms as Magellan for institutional investors and many individual investors in defined contribution plans. This Vanguard index fund very closely tracks the S\&P 500 and it has a $0.05 \%$ fee that is almost perfectly offset by the fund's ability to garner enhanced returns through superior trade execution and its use of index futures.
} 
2002 it had become competitive with most other actively managed large-cap funds by eliminating its load and reducing fees. Even net of stated expenses that came to around $2 \%$ for the three-year period (which, it must be noted, a competent portfolio manager is expected to earn back for his investors), it was still nearly 7\% behind the S\&P 500. This shortfall was cause for alarm at Magellan, which saw over its assets under management decline steadily over the period. ${ }^{4}$ Moreover, software like Quicken made it easy for investors to track Magellan on a daily basis and to detect this sustained pattern of underperformance relative to the index.

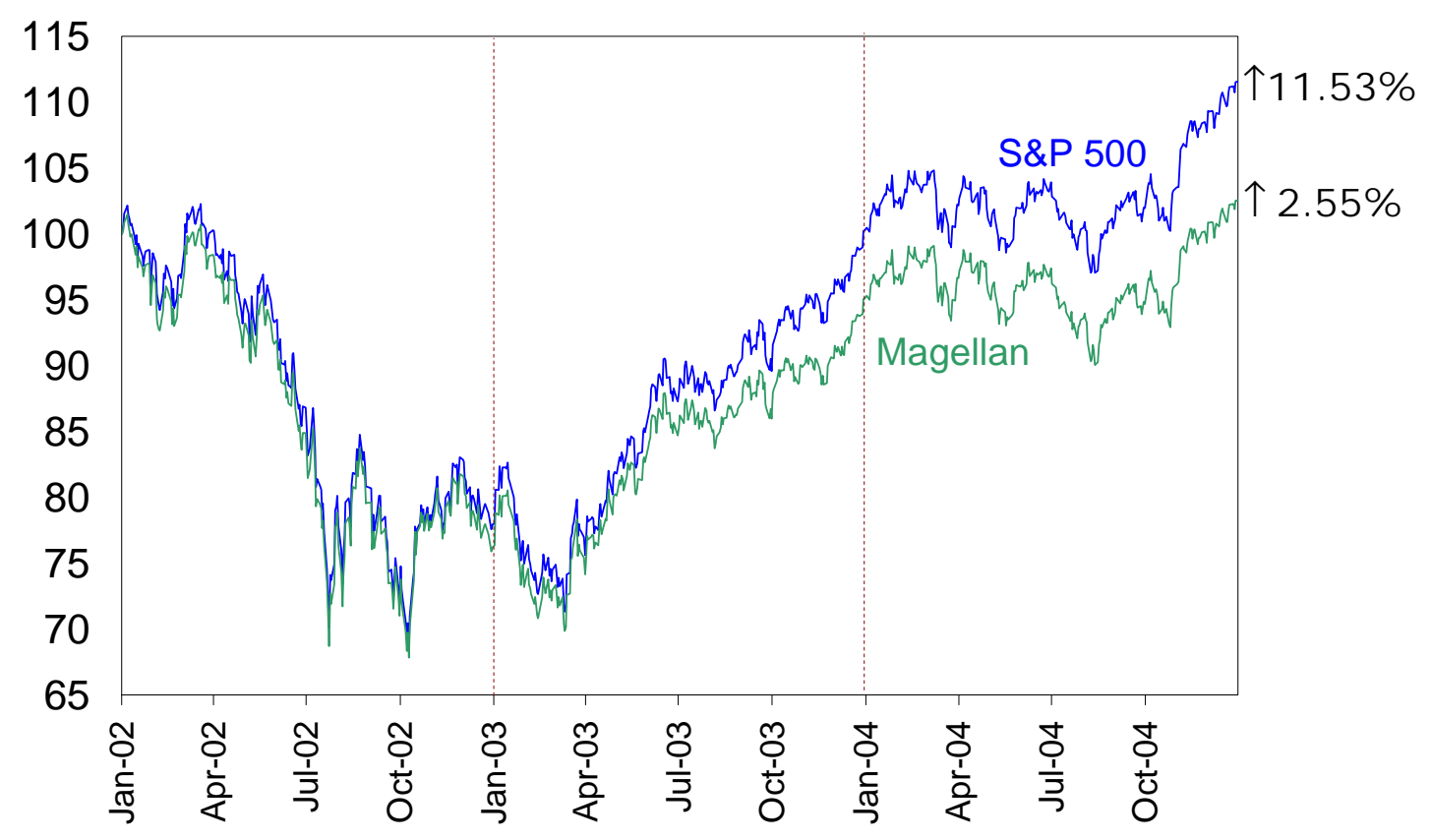

Figure 1. Magellan versus the S\&P 500 between 2002 and 2004.

Daily value of a share with all distributions reinvested and normalized so that the value on December 31, 2001 equals 100. The dotted lines separate the years. The S\&P 500 values are represented by shares of Vanguard Institutional Index Fund. Results derived from NAV and fund distribution data compiled by Commodity Systems, Inc. and downloaded from Yahoo! Finance. All data used in this article was cleaned and spot validated using multiple print and electronic data sources.

\footnotetext{
${ }^{4}$ Magellan has been closed to "new investors" since 1997. Since a defined contribution plan generally counts as a single investor, this closure is not nearly as restrictive as it might appear. While Fidelity may have wanted to shift assets out of Magellan and into some of its other funds, losing assets through underperformance increased the chance that the assets would leave Fidelity's hands entirely. Indeed, it was a standard practice for defined contribution plans to replace Magellan with a large-cap index mutual fund or collective trust from another manager.
} 
In the past, Magellan's deviations from its benchmark might be easily explained: Peter Lynch had his tenbaggers on the upside and Jeffrey Vinik had his bonds on the downside. While we may never know for sure what Robert Stansky had, it is a safe bet that he used computers and that they were the animating force behind his frankenfund.

\section{The Tyranny of Tracking Error}

Despite the Luddite tendencies of Peter Lynch and many of his contemporaries at Fidelity, the company had long embraced information technology. Indeed, it had secured a major competitive advantage over other fund families through the early automation of its back-office functions.

Fidelity's main offices came to be surrounded by smaller competitors who used computer models to help guide their investment choices. Fidelity itself had dabbled in computer-based stock selection. It brought out the Fidelity Disciplined Equity Fund in 1988 shortly after the launch of the Disciplined Stock Fund by Dreyfus, its long-time rival.

Also nestled in Boston's Financial District and in nearby Cambridge were software vendors whose tools made these models possible. Software that could assist a manager in determining the optimal portfolio of holdings for his fund was among the most popular of these tools. By employing computer models that incorporated the Nobel-winning theories of Harry Markowitz and William Sharpe (with refinements from Barr Rosenberg, Fischer Black, Jack Treynor, and others), money managers could readily tweak their portfolios. ${ }^{5}$ After attending a brief seminar, a portfolio manager would know enough to enter his stock picks (and pans) into a computer and have off-the-shelf software construct the theoretically optimal portfolio around them.

The pioneer in portfolio-optimization software was BARRA, a company founded in 1975 by Barr Rosenberg and Andrew Rudd. The appearance of personal computers in the 1980s provided the ideal platform for BARRA's software and the company's success attracted competition. A friend of Peter Lynch, Dan diBartolomeo, founded one of BARRA's more notable competitors, Northfield Information Systems. During Robert Stansky's early days at Magellan, diBartolomeo worked closely with Fidelity to develop new methods of portfolio optimization. ${ }^{6}$ While there is no indication in the published output of this collaboration as to how, if at all, Fidelity used portfolio-optimization software to manage its portfolios, Stansky clearly had access to the technology.

A standard feature of optimization software gave portfolio managers the ability to control the projected "tracking error" of their portfolios relative to a variety of benchmarks that for domestic equities always included the S\&P 500. The manager could also input his own custom benchmark or have the software create its own using style analysis (see Sharpe, 1992). Portfolio managers (or their bosses) who were concerned about style drift could have the software constrain the optimal portfolio to lie within a specified range of expected tracking error.

\footnotetext{
${ }^{5}$ See Bernstein (1992) for a detailed history of portfolio methods and a comprehensive bibliography.

${ }^{6}$ diBartolomeo and Lobosco (1997) contains some concrete results of the collaboration between Northfield and Fidelity. The author also benefited from a private conversation in January 1996 an individual involved in this effort.
} 
As important as tracking error had become for many portfolio managers, nothing remotely like it appeared in the early versions of Markowitz model. Those models were all constructed on the assumption that investors desired to maximize the expected risk-adjusted return (as measured by utility, alpha, Sharpe ratio, etc.) of their portfolios. This assumption was only useful, however, when the portfolio decision-making process was centralized. By the mid-1990s, however, both individual and institutional investors frequently divided their assets among multiple fund managers, each with a different objective or investment style. For this decentralized approach to money management to work as intended, it was important that each manager stick to his style.

Some portfolio managers, either unwittingly or purposefully, began to let minimizing tracking error take precedence over maximizing risk-adjusted return. One part of the problem was that the term "tracking error" brings with it the connotation that any action that the fund manager takes that moves his portfolio away from its benchmark is erroneous. On a phonograph or CD player, tracking error is always bad and less of it is better. Why should it be any different when it comes to investing?

Largely because tracking error arrived late to the portfolio-optimization table, there is no generally accepted definition of it. Most ways of computing tracking error capture the intuition that the more the time series of returns for a portfolio deviates from that of the benchmark, the greater the tracking error. For example, a portfolio that always differs from its benchmark by $0.25 \%$ on a monthly basis might be said to have a monthly tracking error of $0.25 \%$.

Not all deviations from a benchmark, however, are equivalent. Consistent deviations attributable to a manager's outperformance of the benchmark should not count against him. Moreover, deviations that come from the leverage of the portfolio relative to its benchmark should also be netted out.

Linear regression provides a quick and easy way to make both of these adjustments in a single calculation by regressing the returns of the portfolio against those of the benchmark. The constant term in this regression (known as alpha) isolates the performance of the portfolio relative to its benchmark. The linear coefficient on the term(s) specifying the benchmark return (known as beta) adjusts for leverage in the portfolio.

Even with these adjustments, tracking error remains a flawed measure of adherence to a benchmark because it is highly sensitive to changes in market volatility. For example, should market volatility (as measured by the standard deviation of the market's returns) double from $15 \%$ per year to $30 \%$ per year, tracking error will increase substantially if not also double. As a result, an absolute tracking error constraint will be too tight during a period of high market volatility and too loose when volatility is low.

This flaw can be addressed by casting the tracking error in relative terms. The accepted way to make this adjustment is to use the proportion of portfolio variance explained by the variance of the benchmark as a measure of the goodness of fit of the portfolio relative to the benchmark, which is known as $R^{2}$. 
When the tendency for a fund to follow its benchmark is expressed in terms of $R^{2}$, it no longer carries the stigma of being an "error." While institutional portfolios may still include tracking error among their reported statistics for internal use, among investors and academics $R^{2}$ has become the favored metric. For example, Morningstar routinely reports $R^{2} \mathrm{~s}$ (and not tracking error) for the mutual funds it follows. While some portfolio managers may have been conditioned that a high value for tracking error is bad, individual investors have been taught that a high value for $R^{2}$ (which implies low tracking error) is even worse.

John Bogle, the index fund pioneer, popularized the notion that mutual funds with $R^{2}$ s in excess of $95 \%$ that are not marketed as index funds are doing something wrong: they are charging investors for "active" management while providing "passive" management. Such funds have come to be known as either shadow index funds or, more pejoratively, as closet index funds when the fund is perceived to be concealing its actions from investors. Indeed, virtually all shadow index funds can be found deeply in the closet, with corporate mouthpieces denying indexing propensities whenever confronted by financial journalists. While there is no scientific basis for the $95 \%$ cutoff, once a fund's $R^{2}$ tops that level, one has to question what the fund manager is doing to earn fees for active management. ${ }^{7}$

Well before Robert Stansky took its helm, Magellan had become known for shadowing the S\&P 500. During Stansky's tenure, however, this propensity turned extreme. Figure 2 gives the monthly $R^{2}$ for Magellan from 1996 through 2006, a period that brackets the Stansky years. These values for $R^{2}$ were generated by regressing the daily returns of the fund against those of the S\&P 500, as once again represented by the Vanguard Institutional Index Fund. ${ }^{8}$

The monthly $R^{2}$ s are computed using data from the approximately 21 trading days in each month. While this sample may be rather small for making meaningful statistical inferences (36 or 60 monthly data points are often insufficient as well), it is a useful diagnostic that provides a "fresh" estimate each month because there are no overlapping data points in the monthly samples.

Furthermore, the implicit assumption that one is looking at the same portfolio at each point in time is more plausible over a one-month period (or the one-year period examined later in this article) than it is going out 3 to 5 years. Each trading day is treated the same, no adjustment is made for intervening weekends and holidays nor for the delay in receiving distributions from the time that they are accrued. The "industry version" of the returns regressions is employed throughout this article, where gross returns rather than returns net of the "risk-free rate" are used. This is done to emphasize that the results do not depend on any financial model (especially the Capital Asset Pricing Model and its many variants) nor do they depend on the choice of a riskfree rate of return. ${ }^{9}$

\footnotetext{
${ }^{7}$ Bogle (1999, p. 250) lists several criteria for judging whether or not a fund is engaged in closet indexing that includes the $95 \%$ cutoff.

${ }^{8}$ In 1996, the year of the institutional index fund's inception, the retail version of this fund was used.

${ }^{9}$ The key results in this article have been recomputed using net returns with virtually identical results. This is not surprising because money market rates were very low and quite stable between 2002 and 2004 and Magellan's beta was close to unity.
} 


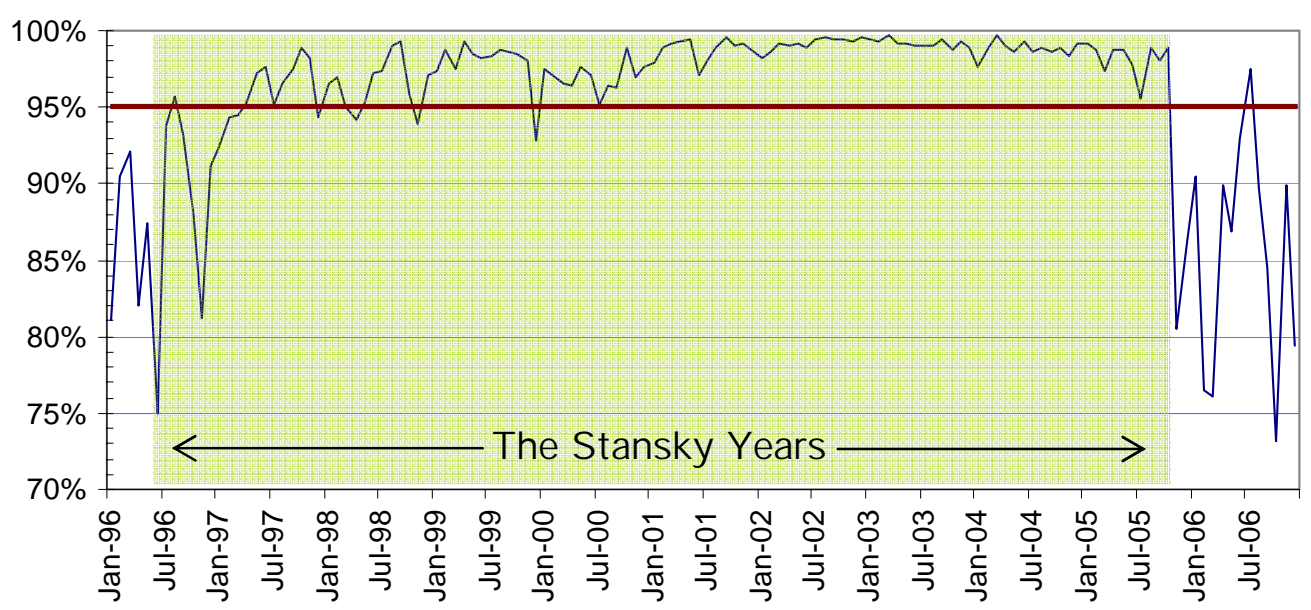

Figure 2. Magellan's Monthly $\boldsymbol{R}^{2}$ Relative to the S\&P 500.

Results derived from NAV and fund distribution data compiled by Commodity Systems, Inc. and downloaded from Yahoo! Finance.

As Figure 2 shows, it took only a year into Stansky's tenure for Magellan to settle into a pattern where the fund's $R^{2}$ dips below $95 \%$ infrequently and flirts with that level for the last time in July 2000. During the 36-month period from January 2002 to December 2004, Magellan's $R^{2}$ stays near $99 \%$, approaching $100 \%$ on several occasions. Only for the single month of January 2004 did Magellan's $R^{2}$ drop under $98 \%$.

If all large-cap stocks had highly correlated returns between 2002 and 2004, then Magellan's magnetic attraction to the S\&P 500 might have been unavoidable. Prevailing circumstances - the war in Iraq, rising energy prices, and big drug problems - created a sizeable dispersion in stock returns. A handcrafted portfolio that did not outright mimic the S\&P 500 would have been unlikely to generate Magellan's pattern of monthly $R^{2} \mathrm{~s}$; a portfolio optimized by computer, however, was a different matter.

Normally, portfolio-optimization software provides benefits because it is able to eliminate inefficiencies that even the most diligent portfolio manager would never detect. Robert Stansky, possibly employing optimization technology proprietary to Fidelity, managed to create a fund that was nominally managed in an active manner and yet never strayed far from the S\&P 500. Could it be that what Robert Stansky did to keep Magellan on track was linked to the fund's underperformance?

\section{Magellan Uncloseted}

A common, but incorrect, way to interpret Magellan's persistent $R^{2}$ of around $99 \%$ between 2002 and 2004 was that the fund was providing its investors with a portfolio that was roughly $99 \%$ 
indexed (or passive management) and $1 \%$ actively managed. If this interpretation of $R^{2}$ were valid, then Magellan's annual shortfall of around 3\% relative to the index would have meant that Robert Stansky lost nearly triple the money that he was actively managing.

Magellan may have performed poorly, but not to the point of losing more money than Robert Stansky was actively managing. The $R^{2}$ statistic, it must be noted, is a measure of variance, and as such is measured in units that are based on the square of portfolio returns and not the returns themselves. This means that it cannot be interpreted as the percentage of the portfolio (either explicitly or implicitly) being invested in the benchmark. It is possible, however, to transform $R^{2}$ into a number that better approximates the portion of the Magellan's funds under active management. Miller (2007) derives this "active share" of the fund's portfolio and shows that it can be computed as $\sqrt{1-R^{2}} /\left(R+\sqrt{1-R^{2}}\right)$. Hence, for a portfolio with an $R^{2}$ of $99 \%$, the implicit share of funds being actively managed is around $9.13 \%$. Under this assessment of the active management that Robert Stansky provided Magellan's investors, he was losing approximately $30 \%$ of the actively managed funds on an annual basis between 2002 and 2004 .

The derivation of the active share is based on the observation that any mutual fund that maintains a consistent investment style can be viewed as bundling together a passive leveraged investment in the benchmark with a purely active investment that is statistically uncorrelated with that benchmark. When the benchmark is a tradable market index, such as the S\&P 500, the active part of the mutual fund is equivalent to a market-neutral hedge fund.

The same framework that is used to convert $R^{2}$ into an active share can also be used to isolate the active component of the mutual fund. Moreover, the purely active ghost that lurks within mutual funds is no theoretical apparition, but rather a viable investment vehicle. All that is required to set a mutual fund free from its closet is to purchase the fund, take an appropriate short position in a futures contract or ETF that holds the benchmark index, and leverage accordingly. While the exact level of returns generated by this naked version of the mutual fund depends on how frequently one re-estimates the regression equation and uses it to rebalance, for stable mutual funds, a simple static hedge provides reveals the active component of the fund manager's performance.

Consider what would have happened if we had isolated the active component of Magellan at the beginning of 2002 and invested in it for the next 3 years. Given that Magellan's beta relative to the S\&P 500 consistently hovered around 1.0, shorting \$1 worth of the index (via futures or ETFs) for each $\$ 1$ in Magellan would effectively strip the passive component from Magellan. Because Magellan's active share for the prior year (2001) was about $12 \%$ (corresponding to an $R^{2}$ between $98 \%$ and $99 \%$ ), one would need to leverage this portfolio up by a factor of 8 to reproduce the same level of exposure to stocks (as measured by the standard deviation of returns) as Magellan itself. ${ }^{10}$

\footnotetext{
${ }^{10}$ This example is constructed using only the information available to investors at the end of 2001. Magellan's realized beta was a little under 1.0; however, its $R^{2}$ was significantly higher than in the preceding period, so roughly 10-to-1 leverage would have been more appropriate. Hence, the example that uses 8-to-1 leverage provides a very conservative estimate of the underperformance of Magellan's active component.
} 
Figure 3 gives the returns of Magellan's inner market-neutral hedge fund. Relative to comparable hedge funds during this period, the active part of Magellan performed so poorly that had it been structured as a hedge fund, it would almost certainly have been forced to cease operations. ${ }^{11}$ Magellan not only performed far worse than the average market-neutral hedge fund between 2002 and 2004, it performed over four times worse than the poorest performing fund in that category tracked by the Center for International Securities and Derivatives Markets. ${ }^{12}$ (The relative monthly net asset values of that fund, the DLIBJ Quantitative Equity Market Neutral Offshore, are also included in Figure 3.)

Magellan's problems did not arise in isolation, and so must be viewed in a broader context. The methods that it used to create its portfolio were likely available in some form to other funds, and especially to those funds from within its own family.

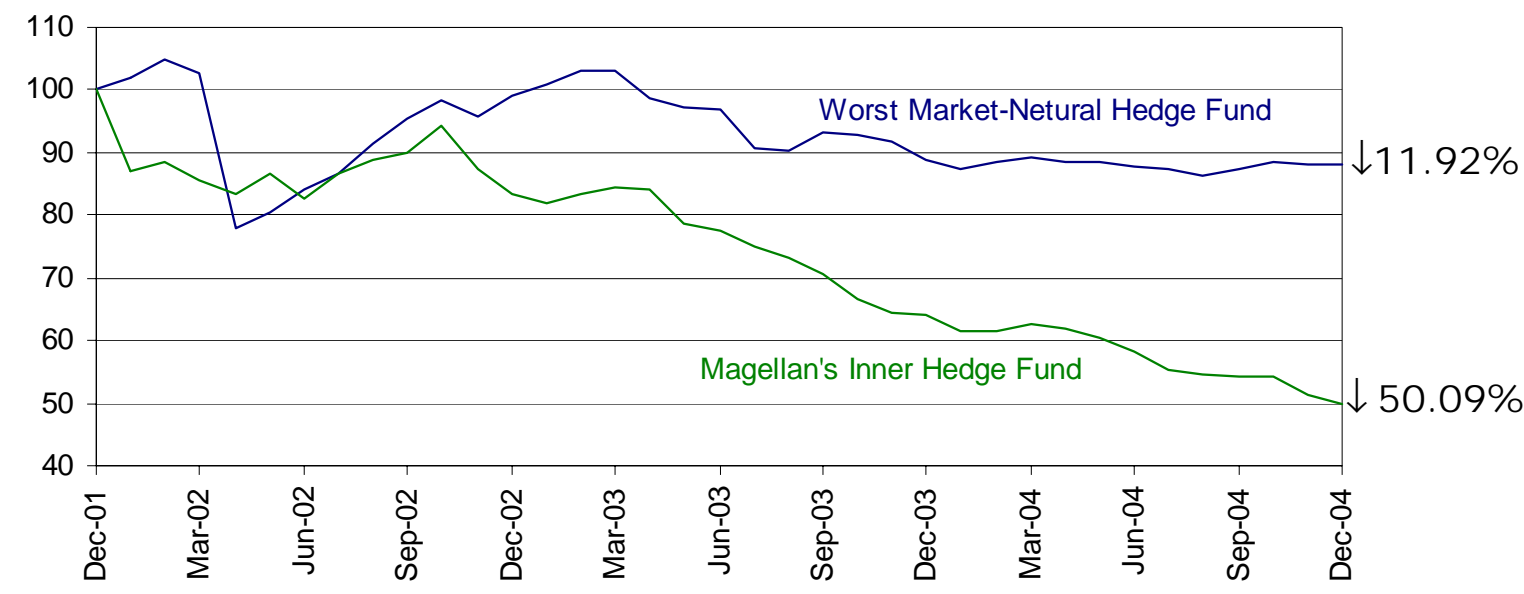

\section{Figure 3. How Magellan's Inner Hedge Fund Measures Up.}

Value of a share with all distributions reinvested normalized so that the value on December 31, 2001 equals 100. Hedge fund values derived from a database provided by the Center for International Securities and Derivatives. Magellan values derived from daily NAV and fund distribution data compiled by Commodity Systems, Inc. and downloaded from Yahoo! Finance.

\footnotetext{
${ }^{11}$ Investors in such an underperforming hedge fund would undoubtedly want to withdraw their assets from it at the first available opportunity. In addition, assuming the fund operated under a standard high-water mark provision, the fund managers themselves would find it advantageous to close the fund rather than wait years until they could once again qualify for performance-based payments.

${ }^{12}$ There may be market-neutral hedge funds with worse performance that either failed to report or did not survive until the end of the sample period, but it is likely that few, if any, approached the abysmal record of Magellan's inner hedge fund.
} 
Magellan may be a giant among shadow indexers, but it shares many attributes with other funds. If Magellan's problems were intrinsic to its size or methods, then one would expect to see many such monsters attacking investor assets. By placing Magellan side-by-side with its peers and subjecting it to greater scrutiny, we might see what contributed to the extreme underperformance documented above.

\section{Magellan and its Brethren}

Between 2002 and 2004, Magellan was the largest of several funds that shadowed the S\&P 500, including a disproportionate number from Fidelity's own financial supermarket. Like Magellan, all of these shadow indexers sport $R^{2}$ s that easily top $95 \%$.

Table 1 shows the 17 Fidelity funds that Morningstar classified as large-cap funds at the end of 2004 as well as the benchmark Vanguard Institutional Index Fund from which the $R^{2}$ s were computed. These funds are ordered from the highest to the lowest average monthly $R^{2}$ relative to the S\&P 500 during that period. The standard deviation of the monthly $R^{2}$ is also presented and it serves as a measure of the consistency with which a fund tracks the index from month to month.

\section{Table 1}

\section{Fidelity Large-Cap Equity Funds: 2002-2004}

All figures with the exception of the monthly $R^{2}$ statistics are derived from Morningstar's December 31, 2004 Principia database. The monthly $R^{2}$ mean and std. dev. are derived from the 36 monthly $R^{2}$ s that are computed by regressing the daily returns of each fund individually against the daily returns of the Vanguard Institutional Index Fund. All daily returns are derived from NAV and fund distribution data compiled by Commodity Systems, Inc. and downloaded from Yahoo! Finance.

\begin{tabular}{|c|c|c|c|c|c|c|c|c|c|c|}
\hline \multirow[b]{2}{*}{ Fund } & \multirow[b]{2}{*}{ Ticker } & \multirow{2}{*}{\multicolumn{2}{|c|}{$\begin{array}{l}\text { Assets } \\
\text { (Millions) }\end{array}$}} & \multirow{2}{*}{$\begin{array}{c}3 \text { Yr Ann. } \\
\text { Return }\end{array}$} & \multirow[b]{2}{*}{ Beta } & \multicolumn{2}{|c|}{ Monthly $R^{2}$} & \multirow{2}{*}{$\begin{array}{l}\text { Active } \\
\text { Share }\end{array}$} & \multirow{2}{*}{$\begin{array}{l}\text { Best Fit } \\
\text { Index }\end{array}$} & \multirow{2}{*}{$\begin{array}{c}\text { Morningstar } \\
\text { Category }\end{array}$} \\
\hline & & & & & & Mean & Std Dev & & & \\
\hline Fidelity Trend & FTRNX & $\$$ & 883 & 3.77 & 1.00 & $99.28 \%$ & $0.48 \%$ & $7.85 \%$ & S\&P 500 & Large Blend \\
\hline Fidelity Magellan & FMAGX & $\$$ & 63,296 & 0.80 & 0.99 & $99.07 \%$ & $0.43 \%$ & $8.85 \%$ & S\&P 500 & Large Blend \\
\hline Fidelity Stock Selector & FDSSX & $\$$ & 822 & 3.29 & 0.98 & $98.75 \%$ & $0.88 \%$ & $10.10 \%$ & S\&P 500 & Large Blend \\
\hline Fidelity & FFIDX & $\$$ & 10,812 & 2.19 & 0.92 & $98.34 \%$ & $1.03 \%$ & $11.50 \%$ & S\&P 500 & Large Blend \\
\hline Fidelity Blue Chip Grth & FBGRX & $\$$ & 23,578 & -0.32 & 0.96 & $98.14 \%$ & $1.21 \%$ & $12.09 \%$ & Russ $1000 \mathrm{Gr}$ & Large Growth \\
\hline Fidelity Disciplined Eq & FDEQX & $\$$ & 4,951 & 5.08 & 0.81 & $97.92 \%$ & $1.37 \%$ & $12.71 \%$ & Russ 1000 & Large Blend \\
\hline Fidelity Adv Gr Opp C & FACGX & $\$$ & 114 & 1.73 & 0.99 & $97.33 \%$ & $1.51 \%$ & $14.22 \%$ & S\&P 500 & Large Blend \\
\hline Fidelity Large Cap Stock & FLCSX & $\$$ & 733 & 0.81 & 0.92 & $97.07 \%$ & $1.90 \%$ & $14.80 \%$ & Russ 1000 & Large Growth \\
\hline Fidelity Growth \& Income & FGRIX & $\$$ & 32,106 & 2.31 & 0.75 & $97.00 \%$ & $1.45 \%$ & $14.96 \%$ & S\&P 500 & Large Blend \\
\hline Fidelity Equity-Inc & FEQIX & $\$$ & 26,372 & 6.21 & 1.01 & $96.08 \%$ & $1.96 \%$ & $16.81 \%$ & Russ 1000 Val & Large Value \\
\hline Fidelity Dividend Growth & FDGFX & $\$$ & 19,422 & 1.27 & 1.07 & $95.08 \%$ & $4.17 \%$ & $18.53 \%$ & S\&P 500 & Large Blend \\
\hline Fidelity Contrafund & FNCTX & $\$$ & 44,485 & 9.99 & 0.54 & $86.15 \%$ & $6.38 \%$ & $28.62 \%$ & S\&P Midcap 400 & Large Growth \\
\hline Fidelity Growth Company & FDGRX & $\$$ & 25,180 & 1.80 & 1.28 & $85.61 \%$ & $10.00 \%$ & $29.08 \%$ & PSE Tech 100 & Large Growth \\
\hline Fidelity Independence & FDFFX & $\$$ & 4,705 & 5.14 & 1.04 & $85.04 \%$ & $9.64 \%$ & $29.55 \%$ & Russ 1000 & Large Growth \\
\hline Fidelity Capital Apprec & FDCAX & $\$$ & 6,452 & 9.94 & 1.13 & $84.92 \%$ & $8.12 \%$ & $29.64 \%$ & Russ 1000 & Large Growth \\
\hline Fidelity OTC & FOCPX & $\$$ & 8,144 & 4.05 & 1.13 & $82.38 \%$ & $9.79 \%$ & $31.62 \%$ & Mstar Small Gr & Large Growth \\
\hline Fidelity Fifty & FFTYX & $\$$ & 892 & 9.07 & 1.00 & $73.49 \%$ & $29.26 \%$ & $37.53 \%$ & Russ 1000 Val & Large Blend \\
\hline Vanguard Inst Idx & VINIX & $\$$ & 34,990 & 3.61 & 1.00 & $100.00 \%$ & $0.00 \%$ & $0.00 \%$ & S\&P 500 & Large Blend \\
\hline
\end{tabular}


Nine of the 17 Fidelity funds have an $R^{2}$ of at least $97 \%$ and two more exceed $95 \%$. Although Magellan comes in second to Fidelity Trend Fund by $0.21 \%$ when ranked by $R^{2}(99.07 \%$ vs. $99.28 \%$ ), its standard deviation of $0.43 \%$ makes it not only the most consistent shadow indexer among Fidelity funds, but of all large-cap funds in the Morningstar universe. (Magellan and Trend are the only two funds with $R^{2}$ s above $99 \%$, although a third Fidelity fund, Stock Selector, is not far behind with an $R^{2}$ of $98.75 \%$.)

Fidelity Trend and Stock Selector may have bracketed Magellan's $R^{2}$ between 2002 and 2004, but they did not bracket its performance. Both funds generated returns roughly in line with the benchmark's 3.61\% annual rate for the three-year period, while Magellan, as noted earlier, lagged considerably. Trend and Stock Selector shadowed the index's performance along every dimension, Magellan did not.

Table 1 indicates that Trend and Stock Selector had far fewer assets to manage than Magellan did. If size is the root of Magellan's problems, however, one would expect Fidelity's other large funds to share in its woes. To the contrary, most of Fidelity's other large funds both performed satisfactorily over the period. Indeed, the second largest Fidelity fund by assets under management, Contrafund, returned nearly $10 \%$ per year with an $R^{2}$ of $86.15 \%$ relative to the S\&P 500. Soon after the end of the sample period, Contrafund would overtake Magellan as the largest Fidelity fund.

A smaller fund that was similar in many ways to Contrafund fund was the Fidelity Capital Appreciation Fund. This fund, which at the time was managed by Robert Stansky's eventual successor, Harry Lange, also returned nearly $10 \%$ annually and had an $R^{2}$ near $85 \%$. Although both funds were categorized as domestic large-cap by Morningstar, each reported substantial holdings outside the S\&P 500 universe, including smaller capitalization and international stocks. Morningstar reports that each of these funds fit another index better than they fit the S\&P 500; however, their returns did not shadow this alternative benchmark nor would they likely track any custom benchmark that would better reflect their heterogeneous equity holdings.

The only large-cap Fidelity fund to experience comparable difficulties to Magellan between 2002 and 2004, Fidelity Blue Chip Growth, also had ample assets under management. With an $R^{2}$ of $98.14 \%$, this fund shadowed the S\&P 500; however, the bulk of its underperformance can be ascribed to a heavy concentration in growth stocks, as one might expect from its name. Despite its history and reputation as a growth fund, Robert Stansky had tempered Magellan's holdings of growth companies, especially those with a technology orientation, to the point where the effect they had on fund performance was statistically negligible. ${ }^{13}$

\footnotetext{
${ }^{13}$ A detailed style analysis of Magellan is not included in this article because contradictory results were obtained depending on the techniques used. To summarize those results, Magellan appears to choose stocks with slightly larger market capitalizations than the average for S\&P 500 stock index and has either a slight growth tilt or a slight value tilt depending on what value and growth indexes are used. Hence, the overall impact of investment style on Magellan's performance is quite minimal.
} 
Table 2 places Magellan in the context of the large-cap funds that had the most assets under management at the end of 2004. Magellan was the only fund of this group not to outperform the S\&P 500. Only the two value-oriented American Funds-Washington Fund and Investment Company of America - also exhibit shadow index tendencies, though to a lesser degree than Magellan. According to Morningstar, the index these funds most closely track is the Russell 1000 Value Index, yet both their $R^{2}$ s are greater than $95 \%$ relative to the S\&P 500 . The other two large non-Fidelity funds, Dodge \& Cox Stock and American Funds Growth, track both their Morningstar benchmarks and the S\&P 500 less closely and are better performers.

Table 2

The Biggest Large-Cap Equity Funds: 2002-2004

Numbers derived in the same manner as Table 1.

\begin{tabular}{|c|c|c|c|c|c|c|c|c|c|}
\hline \multirow[b]{2}{*}{ Fund } & \multirow[b]{2}{*}{ Ticker } & \multirow{2}{*}{$\begin{array}{l}\text { Assets } \\
\text { (Millions) }\end{array}$} & \multirow{2}{*}{$\begin{array}{c}3 \text { Yr Ann. } \\
\text { Return }\end{array}$} & \multirow[b]{2}{*}{ Beta } & \multicolumn{2}{|c|}{ Monthly $R^{2}$} & \multirow{2}{*}{$\begin{array}{l}\text { Active } \\
\text { Share }\end{array}$} & \multirow{2}{*}{$\begin{array}{l}\text { Best Fit } \\
\text { Index }\end{array}$} & \multirow{2}{*}{$\begin{array}{c}\text { Morningstar } \\
\text { Category }\end{array}$} \\
\hline & & & & & Mean & Std Dev & & & \\
\hline Amer Funds Inv Co Am A & AIVSX & $\$ 63,633$ & 5.85 & 0.83 & $95.39 \%$ & $3.02 \%$ & $18.01 \%$ & Russ $1000 \mathrm{Val}$ & Large Value \\
\hline Fidelity Magellan & FMAGX & 63,296 & 0.80 & 0.99 & $99.07 \%$ & $0.43 \%$ & $8.85 \%$ & S\&P 500 & Large Blend \\
\hline Amer Funds Wash A & AWSHX & 61,398 & 5.60 & 0.87 & $95.57 \%$ & $2.08 \%$ & $17.72 \%$ & Russ 1000 Val & Large Value \\
\hline Amer Funds Grth Fund A & AGTHX & 58,164 & 5.08 & 1.00 & $90.41 \%$ & $5.22 \%$ & $24.56 \%$ & Russ 1000 & Large Growth \\
\hline Fidelity Contrafund & FNCTX & 44,485 & 9.99 & 0.54 & $86.15 \%$ & $6.38 \%$ & $28.62 \%$ & S\&P Midcap 400 & Large Growth \\
\hline Dodge \& Cox Stock & DODGX & 41,436 & 12.16 & 0.89 & $90.47 \%$ & $5.28 \%$ & $24.50 \%$ & Mstar Mid Core & Large Value \\
\hline
\end{tabular}

Magellan's combination of shadow indexing and underperformance may have been unusual for a megafund during the 2002-2004 period; however, there were several smaller funds that possessed both these attributes even if not as markedly as Magellan. Table 3 shows the large-cap funds (excluding index funds and "enhanced" index funds) with the highest $R^{2}$ s that had at least $\$ 100$ million in assets under management and underperformed the S\&P 500 between 2002 and 2004. The Morningstar best-fit index for all of these funds was the S\&P 500. Magellan has by far the most assets under management among these laggards.

Table 3

Underperforming Funds that Shadow the S\&P 500: 2002-2004

Numbers derived in the same manner as Tables 1 and 2.

\begin{tabular}{|c|c|c|c|c|c|c|c|c|c|c|}
\hline \multirow[b]{2}{*}{ Fund } & \multirow[b]{2}{*}{ Ticker } & \multicolumn{2}{|c|}{ Assets } & \multicolumn{2}{|l|}{3 Yr Ann. } & \multicolumn{2}{|c|}{ Monthly $R^{2}$} & \multirow{2}{*}{$\begin{array}{l}\text { Active } \\
\text { Share }\end{array}$} & \multirow{2}{*}{$\begin{array}{l}\text { Best Fit } \\
\text { Index }\end{array}$} & \multirow{2}{*}{$\begin{array}{c}\text { Morningstar } \\
\text { Category }\end{array}$} \\
\hline & & & illions) & Return & Beta & Mean & Std Dev & & & \\
\hline Fidelity Magellan & FMAGX & $\$$ & 63,296 & 0.80 & 0.99 & $99.07 \%$ & $0.43 \%$ & $8.85 \%$ & S\&P 500 & Large Blend \\
\hline Dreyfus & DREVX & $\$$ & 1,508 & 1.80 & 0.98 & $98.82 \%$ & $0.68 \%$ & $9.85 \%$ & S\&P 500 & Large Blend \\
\hline Dreyfus Disc Stock & DDSTX & $\$$ & 1,268 & 0.77 & 0.90 & $98.73 \%$ & $0.79 \%$ & $10.20 \%$ & S\&P 500 & Large Blend \\
\hline Dreyfus Growth \& Income & DGRIX & $\$$ & 874 & 0.51 & 1.06 & $98.61 \%$ & $0.72 \%$ & $10.62 \%$ & S\&P 500 & Large Blend \\
\hline Diversified Gr \& In Inv & DVGIX & $\$$ & 594 & 1.62 & 0.98 & $98.50 \%$ & $1.16 \%$ & $10.97 \%$ & S\&P 500 & Large Blend \\
\hline Strong Gr \& Inc Inv & SGRIX & $\$$ & 476 & 1.93 & 0.93 & $98.33 \%$ & $2.46 \%$ & $11.53 \%$ & S\&P 500 & Large Blend \\
\hline Dreyfus Growth Opport & DREQX & $\$$ & 238 & 1.42 & 0.96 & $97.97 \%$ & $1.92 \%$ & $12.58 \%$ & S\&P 500 & Large Blend \\
\hline GE U.S. Equity A & GEEQX & $\$$ & 375 & 2.25 & 0.93 & $97.70 \%$ & $1.75 \%$ & $13.29 \%$ & S\&P 500 & Large Blend \\
\hline Guardian Park Ave A & GPAFX & $\$$ & 982 & 0.08 & 0.91 & $97.60 \%$ & $1.44 \%$ & $13.55 \%$ & S\&P 500 & Large Blend \\
\hline SSgA Core Opportunities & SSGWX & $\$$ & 322 & -1.25 & 0.97 & $97.39 \%$ & $1.97 \%$ & $14.07 \%$ & S\&P 500 & Large Blend \\
\hline
\end{tabular}


This list of shadow indexers is dominated by funds in the Dreyfus family. No Dreyfus fund had a higher $R^{2}$ than the top three Fidelity funds, but three of them approach that level and two of them, the Disciplined Stock Fund mentioned earlier along with the Growth \& Income Fund, returned somewhat less than Magellan did. The worst performing fund of the group was SSgA Core Opportunities and it also had the lowest $R^{2}$.

\section{Dissecting Magellan's Performance}

Magellan's difficulties do not appear to be a direct consequence of any of its obvious attributes. There are funds that in various ways combine being large, a shadow indexer, and a member of the Fidelity family, yet they perform adequately. Perhaps the key to Magellan's woes can be discerned from its observable actions.

Access to Magellan's trading records between 2002 and 2004 could help one isolate the source of the fund's problems. Unfortunately, funds universally consider such information to be proprietary even after it ceases to be timely. As an investment company regulated by the Securities and Exchange Commission (SEC), Magellan is, however, required to make less revealing public disclosures.

The most detailed disclosure that mutual funds provide to the SEC is the semiannual audited statement of the fund's holdings that must be filed within 60 days of the end of the reporting period. Most funds, including Magellan, voluntarily report their holdings more frequently, but these optional reports are usually available only in unaudited form.

While the two audited snapshots of a mutual fund's holdings can provide a general idea of what the fund is doing, it would be unwise to use them as the basis for a formal statistical analysis of the company. Each fund knows ahead of time exactly when the snapshot will be taken and can prepare for it by "window dressing." Based on academic studies, substantial window dressing appears common; hence, any analysis of fund performance based primarily on reported holdings has the potential to be both inaccurate and misleading. ${ }^{14}$

In light of Magellan's high $R^{2}$, one might think that the snapshots of its portfolio would show little more than a blurred picture of the S\&P 500; however, there were real differences between the two. From 2002 to 2004, Magellan's largest holdings significantly overlapped those of the S\&P 500, but there were not identical. For example, Magellan had a far greater share of its portfolio in American International Group and Viacom than did the S\&P 500 index.

In addition to the semiannual listing of fund holdings, registered investment companies also file annual reports and annual prospectuses with the SEC. Typically, annual reports include messages from the head of the fund's management company (Edward C. "Ned" Johnson 3d in the case of Fidelity) and its portfolio manager(s).

\footnotetext{
${ }^{14}$ Kacperczyk, Sialm, and Zheng (2005) demonstrate that there can be a substantial "return gap" between the performance of a fund based on its periodic reported holdings and its actual performance.
} 
Robert Stansky's full statements for the fiscal years ending March 31, 2004 (Fiscal Year 2003 or FY 2003) and March 31, 2005 (Fiscal Year 2004 or FY 2004) are contained in the appendix. Stansky (and Fidelity) used these missives to demonstrate how Magellan deviated from the S\&P index and how these deviations affected the fund's performance. It is interesting to note that as Stansky's performance declined, the space dedicated to his remarks was greatly reduced and his headshot no longer appeared beside them.

Robert Stansky's explanation for FY 2003 (Fidelity Management and Research Company, 2004), a period in which the fund lagged the index by $4.77 \%$, began by singling out his decision to underweight technology companies like Intel and Cisco as the primary reason for Magellan's poor performance. Problems at traditional media outlets (Viacom and Clear Channel) as well as at pharmaceuticals giant Merck were also cited. Although a detailed accounting of the fund's holdings at the end of the reporting period followed Mr. Stansky's statement, no numbers were provided that would indicate how much of Magellan's $4.77 \%$ shortfall was caused by these explicit departures from the index.

One can read into Robert Stansky's statements that he viewed Magellan's portfolio along industry lines. Indeed, Stansky's allocation of assets at the industry level was consistently different from those of the S\&P 500 throughout the 2002-2004 timeframe.

Figure 4 provides a graphical comparison of Magellan's industry holdings with those of S\&P 500. The numbers underlying this figure, which is broadly representative of the 2002-2004 period, were reported on September 30, 2003, the midpoint of FY 2003. The most obvious difference between Magellan and the S\&P 500 at the industry level is that Robert Stansky had an extreme aversion to utility stocks - one that dates back to before the Enron collapse. (The last utility company in which Magellan held a sizable stake was Enron.) While this unaudited snapshot of Magellan's portfolio confirms that it was underweight in technology, the shortfall amounts to less than 3\% of the portfolio's assets when both software and hardware companies are taken together. Even if the technology companies that were underrepresented in Magellan's portfolio outperformed the S\&P 500 by a full $20 \%$ in absolute annual returns, the $0.60 \%(20 \%$ of $3 \%$ ) that this would reduce Magellan's returns relative to the benchmark accounts for only about one-eighth of the $4.77 \%$ shortfall. Moreover, Robert Stansky's correct call on financial stocks appears to have offset any problems he had with tech stocks.

Banks and insurance companies may have benefited Stansky and Magellan in FY 2003, but they would be his biggest problem the following year. Combined with an unflagging dedication to media companies, financials led Magellan to lag the S\&P 500 once again in FY 2004, this time by $3.55 \%$. While this would appear to be an improvement from $4.77 \%$ in FY 2003, the rise in Magellan's beta (relative to the S\&P 500) of Magellan's portfolio, due in large part to a belated move into tech stocks, had the effect of further depressing the fund's alpha. As in the previous year, Magellan had a big industry winner that would take the edge off its losers. The fund had stuck with energy stocks and would reap the benefits of a sustained spike in oil and natural gas prices. 


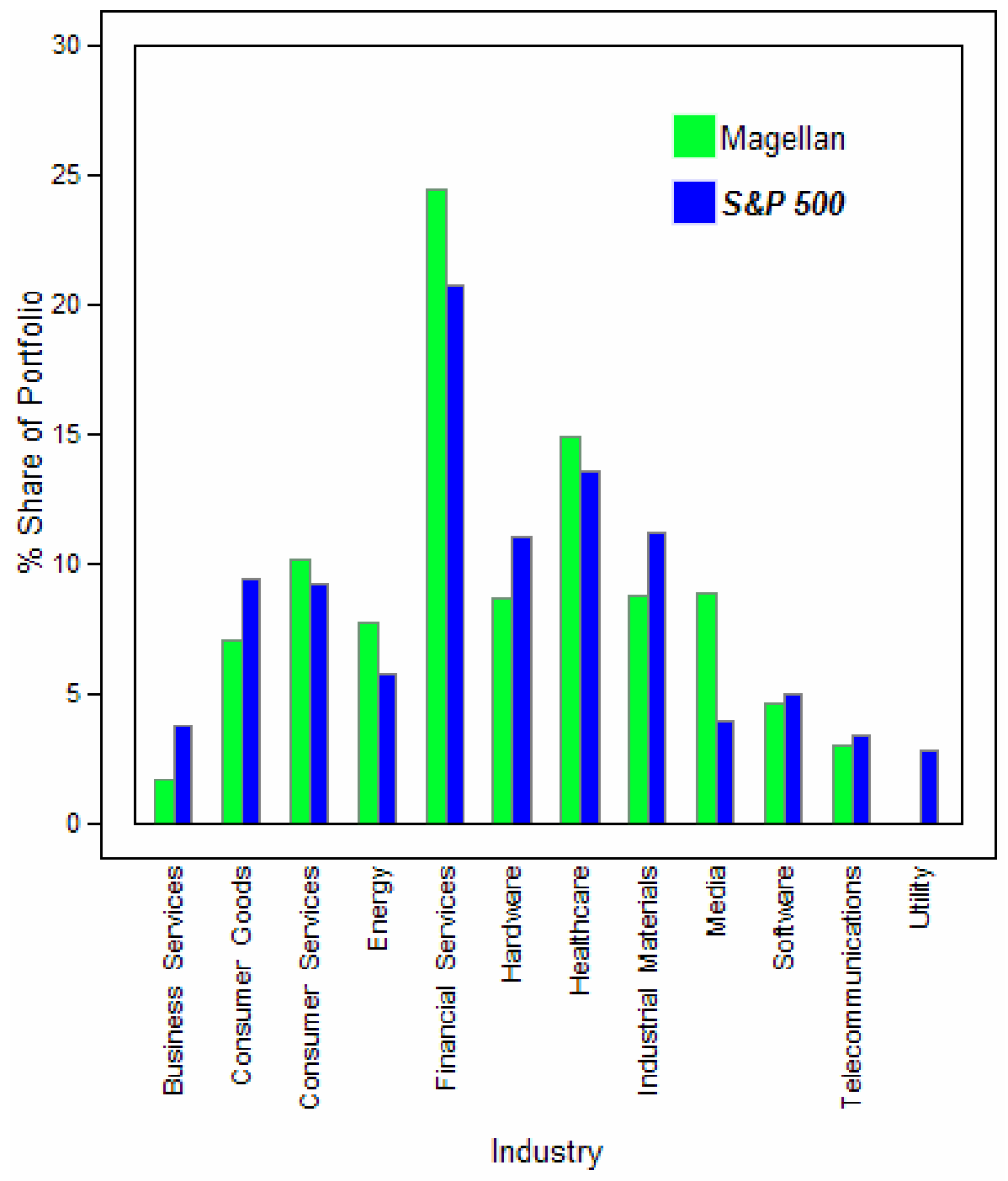

Figure 4. Magellan's Industry Composition vs. the S\&P 500.

Source: Morningstar Principia December 31, 2003 database. Numbers reported for the period ending September 30, 2003.

Even under the more rigorous standards imposed by Sarbanes-Oxley, mutual funds are not required to "account for their losses" at either an industry or company level. Nonetheless, one can estimate the effect of Magellan's industry exposure on its performance using another source of information each fund provides to the public - the daily accounting of its net asset value (NAV). While researchers, for whom monthly NAVs are more readily available in major fund databases, rarely incorporate daily returns into their analyses, the approximately 252 daily 
returns data points over the course of a year provide a potential cornucopia of information about a fund that can be extracted via linear regression. Although the analysis of these returns is subject to the usual limitations of any statistical method, they are minimally influenced by window dressing because they "reverse engineer" a fund's industry exposure from its returns over an extended period of time during which the fund's portfolio is presumably invisible to investors with only a handful of observations before, on, and after each reporting date being corrupted by any attempt to disguise the portfolio.

Linear regression is an appropriate tool because if one decomposes a portfolio into its components, the portfolio's returns are approximately a weighted sum of these components net of any fees imposed by the manager. Hence, we can write:

$$
r_{P} \cong \sum_{i=1}^{N} w_{i} r_{i}-f_{P}^{c}-f_{P}^{v}
$$

where $r_{P}$ is the portfolio's return, $w_{i}$ is the weight of the $i^{\text {th }}$ component of the portfolio, $r_{i}$ is the return of the $i^{\text {th }}$ component, $f_{P}{ }^{c}$ is the fixed fee associated with the portfolio and $f_{P}{ }^{v}$ is the variable fee. Because returns are primarily generated by events (price changes, dividends, etc.) that also change a component's weight in the portfolio, (1) is expressed an approximation that is most accurate for the small values of $r_{i}$ that are typical of daily returns. For a fund that charges a management fee, that fee is generally assessed on a daily basis rather than as periodic discrete payments, and so constitutes the fixed component, $f_{P}{ }^{c}$. Fees that are variable, such as those associated with trading or with other forms of slippage constitute the variable fee component, $f_{P}{ }^{v}$. While this approximation holds in a literal sense if the components of the portfolio are either the individual securities that compromise the portfolio, it also applies to a factor-based decomposition of the portfolio along the lines of industries, sectors, or styles.

Formula (1) can be recast in regression form as:

$$
r_{P t}=\alpha+\sum_{i=1}^{N} \beta_{i} r_{i t}+\varepsilon_{t}, \quad t=1, \ldots, T
$$

For an exact decomposition of the portfolio into its components, the estimate of $\beta_{i}$ should correspond to its weight, $w_{i}$ in the portfolio. The constant term, $\alpha$, will capture both the fixed fee and the average amount of the variable fee. ${ }^{15}$ What is left in the error term, $\epsilon_{t}$, is the deviation of the variable fee from its mean as well as with various noise that includes the error inherent in any approximation.

Equation (2) is of a general form that subsumes most common models used to estimate portfolio performance including the Capital Asset Pricing Model (CAPM), the Fama-French model, and models based on arbitrage pricing theory (APT). These models, however, are not derived from a literal decomposition of the portfolio into its component parts as suggested by (1), but are based on financial theories that statistically relate the portfolio's returns to those of its underlying factors. Under these interpretations, the betas represent the factor loadings and alpha is a measure

\footnotetext{
${ }^{15}$ In order for all fees to be captured by alpha, the individual components must not contain any fees. That is why a Vanguard fund that is equivalent to a feeless version of the index portfolio is used to represent the index.
} 
of the portfolio's performance relative to these loadings. In practice, just a few factors are used to gauge a mutual fund's performance. Both the traditional CAPM and the best-fit benchmark approach employed by Morningstar consider only a single factor and the Fama-French model uses three (or four, if a momentum factor is included).

What is necessary to understand Magellan's underperformance is not a better measurement of alpha-all standard performance measures indicate that it underperformed any reasonable factorderived benchmark between 2002 and 2004 - but rather a consistent and confirmable attribution of the fund's shortfall. Ideally, if one included enough relevant factors in the right-hand side of the regression equation (2), one could isolate the sources of Magellan's underperformance in the form of estimated factor weights. The alpha that would remain in such a regression would be a negative number that should closely match the daily expense of running the fund.

Table 4 provides a statistical overview of Magellan both in the time period under examination (Fiscal Years 2003 and 2004) as well as for the two years prior to this period and the year that follows it. All analysis is done using fiscal years instead of calendar years because Robert Stansky's explanations for Magellan's performance were made in the context of the fund's fiscal year results. FY 2004 extends three months into calendar year 2005, the beginning of a new regime with lower and more erratic $R^{2}$ s. (From here on, 2003 and 2004 are understood to refer to FY 2003 and FY 2004, respectively.) ${ }^{16}$ The withdrawal of assets from the fund accelerated in 2004 and continued into the following year.

Magellan's turnover is of particular interest. During the two years with the worst performance, 2003 and 2004, years that are also the focus of the analysis that follows, the fund's turnover was especially low, 13\% and 6\%, respectively. Assuming that these numbers accurately reflect the activity within the fund (this will be discussed later in the article), these are more typical of index funds than of actively managed funds (except for some tax-managed funds).

One advantage of the presumably low turnover is that it makes it easier to derive meaningful estimates of the factor loadings in equation (2), especially over extended periods of time. Robert Stansky does appear to have kept his bets on financial services, energy, and utility in place throughout 2003 and 2004. The move into technology companies noted above looks to have been Stansky's only major shift in the portfolio during that period.

The bottom section of Table 4 provides the results regression Magellan's daily returns against those of the Vanguard Institutional Index Fund for each of the five years and for 2003 and 2004 taken together. T-statistics are reported for all estimated coefficients. For alpha, a separate tstatistic is reported that measures how much alpha differs from the negative of the pro-rated daily expense of running the fund. The stated expense component of Magellan's underperformance is already known, what is of interest is where the rest of the money went.

\footnotetext{
${ }^{16}$ Using standard calendar years and other slices of time, has little effect on the reported results. Magellan's early underperformance from 2002 is counted in FY 2001 rather than FY 2002, so for FY 2002 Magellan slightly outperforms the S\&P 500 even though in the corresponding calendar year it underperforms it. The results for FY 2003 and FY 2004, however, are quite similar to their corresponding calendar years.
} 
Table 4

Statistical Summary of Fidelity Magellan Fund: FY 2001-FY 2005

All figures in the top part of the table are taken directly from Magellan's annual reports for the fiscal years in question except to the aggregate FY 2003-2004 summary and the daily expense ratios that are derived from those figures (Fidelity Management and Research Company, 20022006). The regression results in the bottom part of the table are computed using daily returns that are derived from NAV and fund distribution data compiled by Commodity Systems, Inc. and downloaded from Yahoo! Finance.

\begin{tabular}{|c|c|c|c|c|c|c|}
\hline & $\begin{array}{c}\text { FY } \\
2001\end{array}$ & $\begin{array}{c}\text { FY } \\
2002 \\
\end{array}$ & $\begin{array}{c}\text { FY } \\
2003\end{array}$ & $\begin{array}{c}\mathrm{FY} \\
2004\end{array}$ & $\begin{array}{c}\text { FY } \\
2003-2004 \\
\end{array}$ & $\begin{array}{c}\text { FY } \\
2005 \\
\end{array}$ \\
\hline Total return & $-0.76 \%$ & $-24.65 \%$ & $30.35 \%$ & $3.14 \%$ & $34.44 \%$ & $15.89 \%$ \\
\hline $\begin{array}{l}\text { Benchmark } \\
(\text { S\&P 500) return }\end{array}$ & $0.24 \%$ & $-24.76 \%$ & $35.12 \%$ & $6.69 \%$ & $44.16 \%$ & $11.73 \%$ \\
\hline $\begin{array}{l}\text { Expense Ratio: } \\
\text { Entire Period } \\
\text { Daily } \\
\end{array}$ & $\begin{array}{c}0.88 \% \\
0.358 \text { b.p. }\end{array}$ & $\begin{array}{c}0.76 \% \\
0.300 \text { b.p. }\end{array}$ & $\begin{array}{c}0.70 \% \\
0.277 \text { b.p. }\end{array}$ & $\begin{array}{c}0.62 \% \\
0.247 \text { b.p. }\end{array}$ & $\begin{array}{c}1.32 \% \\
0.262 \text { b.p. }\end{array}$ & $\begin{array}{c}0.56 \% \\
0.221 \text { b.p. }\end{array}$ \\
\hline $\begin{array}{l}\text { Share NAV } \\
\text { end of period }\end{array}$ & $\$ 102.55$ & $\$ 76.69$ & $\$ 99.13$ & $\$ 101.00$ & $\$ 101.00$ & $\$ 112.80$ \\
\hline $\begin{array}{c}\text { Net assets under } \\
\text { management } \\
\text { end of period } \\
\text { (in millions) } \\
\end{array}$ & $\$ 78,818$ & $\$ 54,164$ & $\$ 66,797$ & $\$ 56,891$ & $\$ 56,891$ & $\$ 50,473$ \\
\hline $\begin{array}{l}\text { Net assets } \\
\quad \text { withdrawn } \\
\text { (in millions) }\end{array}$ & $\$ 692$ & $\$ 4,294$ & $\$ 3,155$ & $\$ 16,750$ & $\$ 19,905$ & $\$ 17,229$ \\
\hline $\begin{array}{l}\text { Portfolio turnover } \\
\text { rate }\end{array}$ & $15 \%$ & $21 \%$ & $13 \%$ & $6 \%$ & N/A & $74 \%$ \\
\hline $\begin{array}{l}\text { Daily returns vs. } \\
\text { S\&P } 500\end{array}$ & $\begin{array}{c}\text { FY } \\
2001 \\
\end{array}$ & $\begin{array}{c}\text { FY } \\
2002 \\
\end{array}$ & $\begin{array}{c}\mathrm{FY} \\
2003\end{array}$ & $\begin{array}{c}\text { FY } \\
2004 \\
\end{array}$ & $\begin{array}{c}\text { FY } \\
2003-2004 \\
\end{array}$ & $\begin{array}{c}\mathrm{FY} \\
2005\end{array}$ \\
\hline $\begin{array}{l}\text { Alpha } \\
\left(\mathrm{t}_{0}\right) \\
\left(\mathrm{t}_{\exp }\right)\end{array}$ & $\begin{array}{c}-0.402 \text { b.p. } \\
(-0.50) \\
(-0.05)\end{array}$ & $\begin{array}{l}\text { 0.111 b.p. } \\
\quad(0.13) \\
(0.47)\end{array}$ & $\begin{array}{c}-1.158 \text { b.p. } \\
(-2.14) \\
(-1.63)\end{array}$ & $\begin{array}{c}-1.380 \text { b.p. } \\
(-2.65) \\
(-2.18)\end{array}$ & $\begin{array}{c}-1.322 \text { b.p. } \\
(-3.48) \\
(-2.79)\end{array}$ & $\begin{array}{c}\text { 1.335 b.p. } \\
(1.04) \\
(1.21)\end{array}$ \\
\hline $\begin{array}{l}\text { Beta } \\
(\mathrm{t})\end{array}$ & $\begin{array}{c}0.971^{* *} \\
(149.22)\end{array}$ & $\begin{array}{l}1.011^{* *} \\
(196.63)\end{array}$ & $\begin{array}{l}0.978^{* *} \\
(156.37)\end{array}$ & $\begin{array}{l}1.014^{* *} \\
(130.46)\end{array}$ & $\begin{array}{l}0.991^{* *} \\
(202.30)\end{array}$ & $\begin{array}{l}1.034^{* *} \\
(51.15)\end{array}$ \\
\hline $\begin{array}{l}\text { Observations } \\
R^{2} \\
\text { Durbin-Watson } \\
\end{array}$ & $\begin{array}{c}246 \\
0.9892 \\
1.9572 \\
\end{array}$ & $\begin{array}{c}253 \\
0.9936 \\
1.9682 \\
\end{array}$ & $\begin{array}{c}253 \\
0.9898 \\
1.8905 \\
\end{array}$ & $\begin{array}{c}251 \\
0.9856 \\
2.0379 \\
\end{array}$ & $\begin{array}{c}504 \\
0.9879 \\
2.0141 \\
\end{array}$ & $\begin{array}{c}253 \\
0.9125 \\
1.8403 \\
\end{array}$ \\
\hline
\end{tabular}


Before examining these regression results, some cautionary words are in order. The use of daily data may provide us with many more observations that monthly or even weekly data; however, the magnitude of the effects that are to be isolated begins to approach the noise floor of our data. Specifically, the shortfall of Magellan relative to the S\&P 500 that we wish to explain does not exceed 1 basis point per trading day by very much even when the fund is underperforming the most. ${ }^{17}$ This daily shortfall only slightly exceeds the smallest possible movement in Magellan's reported NAV, which is a single cent per share of a fund that trades around $\$ 100$.

Not only does the quantization of Magellan's share price contribute to the error term for any regression involving its daily returns, the variable portion of the fund's shortfall is sizeable relative to the fixed portion associated with known expenses. Suppose, for example, that Fidelity had simply shifted funds from Magellan to elsewhere in Fidelity or outside the firm. If the same percentage of funds were shifted every day, this activity would show up in the constant term. If this reallocation of funds occurred sporadically, however, it would drop directly into the error term and the added noise would reduce the statistical significance of the constant term.

Despite the inherent limitations of daily data, Table 4 shows that Magellan's underperformance during 2003 and 2004 was statistically significant. The level of significance increases substantially when data from the two years is pooled together into a single regression. Netting out stated expenses does drop the t-statistic on Magellan's alpha for 2003 below the 5\% significance level; however, alpha for both 2004 and for 2003 and 2004 remain significant, at the $5 \%$ and $1 \%$ levels, respectively. ${ }^{18}$ While this simple regression is useful for establishing a baseline for Magellan's performance, it is somewhat misspecified considering what is known about the fund and this misspecification further degrades the significance of the estimates. Serial correlation, however, is never an issue, as the Durbin-Watson statistics presented along with the regression estimates indicate.

As stated in an earlier footnote, the application of traditional style-based performance attribution analysis to Magellan's returns is revealing only in that it reveals almost nothing. At a macro level, Magellan's portfolio appears to have been designed to track the S\&P 500. Any correlations with other growth/value or capitalization-based benchmarks that remain after the effect of the S\&P 500 has been netted out of Magellan's returns are transitory.

Robert Stansky claims that Magellan's results are influenced by his industry weightings, so the addition of industry returns to the regression should account for a substantial portion of the fund's underperformance. The results in Table 5, however, show that this is not the case. Daily industry portfolio returns from the Fama-French online research database are included in the returns regression in order to capture industry effects. ${ }^{19}$ The Fama-French industry portfolios

\footnotetext{
${ }^{17}$ Daily compounding of returns introduces a significant nonlinearity into the analysis. The affect of a daily shortfall of 1 basis point on annualized returns depends on the magnitude of the returns-as returns increase so will the annual shortfall.

${ }^{18}$ The inclusion of year-based dummy variables in the two-year regression has little effect on the results.

${ }^{19}$ Results of the capitalization-weighted 12-industry partition are reported here; however, the results are similar for other industry breakdowns except for 2004 when the partitioning becomes so fine that most industries are dominated by a single company. This exception is consistent with the results that follow.
} 
draw companies from beyond the $\mathrm{S} \& \mathrm{P} 500$, so their returns relative to that index also capture the effect of smaller capitalization companies along with any industry effects. Because Magellan is concentrated in large-cap stocks, this has no meaningful effect on the regression results.

The industry coefficients in Table 5 can be interpreted as an estimate of Magellan's industry weightings relative to the S\&P 500. For example, the business equipment industry, which is dominated by computer hardware and software companies that include Intel and Cisco, has a coefficient of -0.033 , indicating that this industry is approximately $3.3 \%$ underweighted relative to the S\&P 500, which is consistent with the holdings reported by Magellan. For 2003, the business equipment industry beat the S\&P 500 by 4.36 basis points a day (16.63 vs. 12.27), which comes to somewhat over $10 \%$ per year, far less than the liberal estimate of $20 \%$ used earlier. No matter how one twists the numbers, it is clear that technology stocks were not the root of Magellan's problems in 2003.

Indeed, when one takes into account all twelve industries and not just the worst one, the estimated shortfall actually rises in magnitude, from the -1.158 basis point daily shortfall that appeared in Table 4 up to -1.260 basis points. Furthermore, because the regression equation is now closer to the proper specification, the shortfall is significant at the $1 \%$ level before expenses are taken into account and at the 5\% level after they are taken into account. The absence of utility stocks from Magellan's portfolio, while apparent in the estimates, had little effect on returns and the other industry-level deviations from the S\&P 500 were largely offsetting.

Fiscal year 2004 tells a similar story at the industry level; however, this time poor industry selection explains a small portion of Magellan's underperformance, reducing it from -1.380 to -1.143 basis points per day. As one would expect, financial services companies are the problem, but not nearly to the degree that Magellan's annual report makes them out to be. Stansky's energy bet paid off handsomely; however, his shift into computer technology-the $3.3 \%$ underweighting in business equipment in 2003 becomes a 1.8\% overweighting in 2004accomplished little.

As before, combining the two years into a single regression has the effect of increasing the significance of alpha, pushing it well beyond the $1 \%$ level regardless of whether stated expenses are netted out or not. The effect on the magnitude of alpha is roughly the average of the separate 2003 and 2004 effects and the inclusion of industry returns reduces alpha from -1.322 to -1.212 basis points per day.

Considering the small and insignificant differences the inclusion of broad industry groupings make on the constant term of the returns regression, the source of Magellan's difficulties might be found if one were only to dig deeper into the portfolio. A natural next step would be to include additional explanatory variables in the regression and see what they reveal. The problem with this approach is that over a full year, regardless of how that time is divided up, there is a 


\section{Table 5}

\section{Industry Decomposition of Magellan's Daily Returns}

All daily returns for Magellan and the S\&P 500 (Vanguard Institutional Index Fund) are derived from NAV and fund distribution data compiled by Commodity Systems, Inc. and downloaded from Yahoo! Finance. Daily industry returns are taken directly from the Fama-French research database. Parentheses contain t-statistics and the superscripts ${ }^{*}$ and ${ }^{* *}$ indicate significance at the $5 \%$ and $1 \%$ levels, respectively.

\begin{tabular}{|c|c|c|c|}
\hline & FY 2003 & FY 2004 & FY 2003-2004 \\
\hline $\begin{array}{l}\text { Alpha } \\
\left(\mathrm{t}_{0}\right) \\
\left(\mathrm{t}_{\mathrm{exp}}\right)\end{array}$ & $\begin{array}{l}-1.260 \text { b.p. } \\
(-2.65) \\
(-2.06)\end{array}$ & $\begin{array}{l}-1.143 \text { b.p. } \\
(-2.51) \\
(-1.97)\end{array}$ & $\begin{array}{l}-1.212 \text { b.p. } \\
(-3.49) \\
(-2.74)\end{array}$ \\
\hline S\&P 500 & $\begin{array}{c}0.927^{* *} \\
(16.48)\end{array}$ & $\begin{array}{c}0.933^{* *} \\
(14.79)\end{array}$ & $\begin{array}{c}0.886^{* *} \\
(20.40)\end{array}$ \\
\hline Bus. Equip. & $\begin{array}{l}-0.033^{* *} \\
(-3.05)\end{array}$ & $\begin{array}{c}0.018 \\
(1.52)\end{array}$ & $\begin{array}{c}-0.001 \\
(-0.14)\end{array}$ \\
\hline Chemicals & $\begin{array}{l}-0.012 \\
(-0.92)\end{array}$ & $\begin{array}{l}-0.032^{*} \\
(-2.48)\end{array}$ & $\begin{array}{l}-0.012 \\
(-1.27)\end{array}$ \\
\hline Durables & $\begin{array}{c}0.012 \\
(1.41)\end{array}$ & $\begin{array}{l}-0.018 \\
(-1.82)\end{array}$ & $\begin{array}{c}0.002 \\
(0.28)\end{array}$ \\
\hline Energy & $\begin{array}{l}0.024^{* *} \\
(3.18)\end{array}$ & $\begin{array}{l}0.027^{* *} \\
(3.89)\end{array}$ & $\begin{array}{l}0.029^{* *} \\
(5.66)\end{array}$ \\
\hline Health & $\begin{array}{c}0.003 \\
(0.28)\end{array}$ & $\begin{array}{l}0.021^{*} \\
(2.02)\end{array}$ & $\begin{array}{c}0.017^{*} \\
(2.22)\end{array}$ \\
\hline Manufacturing & $\begin{array}{l}-0.019 \\
(-1.21)\end{array}$ & $\begin{array}{c}-0.014 \\
(-0.80)\end{array}$ & $\begin{array}{c}-0.023 \\
(-1.82)\end{array}$ \\
\hline Money/Finance & $\begin{array}{l}0.067^{* *} \\
(3.52)\end{array}$ & $\begin{array}{c}0.050^{*} \\
(2.41)\end{array}$ & $\begin{array}{c}0.067^{* *} \\
(4.56)\end{array}$ \\
\hline Nondurables & $\begin{array}{l}-0.000 \\
(-0.01)\end{array}$ & $\begin{array}{l}-0.019 \\
(-1.35)\end{array}$ & $\begin{array}{c}0.000 \\
(0.01)\end{array}$ \\
\hline Others & $\begin{array}{c}0.018 \\
(1.31)\end{array}$ & $\begin{array}{c}0.008 \\
(0.45)\end{array}$ & $\begin{array}{c}0.019 \\
(1.58)\end{array}$ \\
\hline Retail & $\begin{array}{c}0.021 \\
(1.92)\end{array}$ & $\begin{array}{c}0.023 \\
(1.83)\end{array}$ & $\begin{array}{l}0.026^{* *} \\
(2.99)\end{array}$ \\
\hline Telecom & $\begin{array}{c}0.014 \\
(1.83)\end{array}$ & $\begin{array}{l}0.060^{* *} \\
(4.95)\end{array}$ & $\begin{array}{l}0.023^{* *} \\
(3.44)\end{array}$ \\
\hline Utilities & $\begin{array}{l}-0.046^{* *} \\
(-5.28)\end{array}$ & $\begin{array}{l}-0.048^{* *} \\
(-5.39)\end{array}$ & $\begin{array}{l}-0.052^{* *} \\
(-7.93)\end{array}$ \\
\hline Observations & 253 & 251 & 504 \\
\hline$R^{2}$ & 0.9931 & 0.9902 & 0.9905 \\
\hline Durbin-Watson & 1.9421 & 2.1414 & 2.0718 \\
\hline
\end{tabular}


limit to the independent movements of variables that can be used to explain the roughly $1 \%$ of Magellan's that is not explained by the S\&P 500. (The “noise floor" on Magellan's daily returns would appear to guarantee that at least $0.25 \%$ of the portfolio's variance in returns will defy explanation by any means.) If one could independently determine the values of the independent variables - allowing one, for example, to explore what would happen to Magellan on a day when bank stocks were up $2 \%$ and insurance stocks were down $2 \%$, uncovering what was behind Magellan's underperformance would be relatively easy. Unfortunately, Magellan's major influences tend to move together and this multicollinearity not only makes it hard to isolate what moves Magellan, but also injects noise into the estimation procedure. Standard techniques for reducing the number of the independent variables, such as principal components analysis and the much-disparaged stepwise regression, do not lead to any fundamentally different results from those reported here - the estimate of Magellan's alpha and its statistical significance remain largely unchanged. ${ }^{20}$

Given that Robert Stansky singles out several stocks by name as the source of Magellan's woes, their returns are obvious candidates for explanatory variables. Similarly, finer partitions of companies into "subindustries" generate similar results because of the previously noted tendency for a single company to dominate a subindustry when capitalization-weighted returns are used. The problem with any industry breakdown is that the arbitrary assignment of multifunctional companies, which are disproportionately those with the largest capitalization, to a single industry introduces error into the regression. A handful of representative companies that are either significantly overweighted or underweighted in the portfolio relative to the benchmark can do a better job of capturing not only their direct effect on returns, but also those of similar companies in the portfolio with highly correlated returns.

Table 6 provides the results for 2003 and 2004 both separately and together in a single two-year regression. Overlapping companies in an industry have been eliminated from the regressions in an effort to reduce multicollinearity. For example, Cisco represents the high tech companies held by Magellan (as opposed to those in its "industry" as a whole) and Clear Channel represents the traditional broadcasters. The addition of redundant companies generally fails to explain the small amount of variance in Magellan's returns that remains unexplained. Other regressions were run that also included Magellan's largest holdings_-Exxon Mobil, GE, Microsoft, etc.—and various industry returns. The addition of these variables, even when judiciously pruned, contributed little to the explanation of Magellan's underperformance.

As Table 6 shows, the inclusion of stock returns in the regression does not help matters in 2003 - alpha goes up by an insignificant 0.004 basis points. Overall, the estimated coefficients of the regression are of the sign and magnitude that one would expect from the Stansky narrative except for Cisco, which gets a weight of less than $1 \%$ in the portfolio. (Intel received even less weight and explained less of Magellan's underperformance than Cisco when it was substituted for it.) As was the case for the industry regressions, including stocks in the mix increases the

\footnotetext{
${ }^{20}$ Unsurprisingly, when principal components analysis is applied to large-cap mutual funds, the principal components correspond closely to traditional investing styles.
} 
Table 6

Industry Decomposition of Magellan's Daily Returns

All daily returns for Magellan, the S\&P 500 (Vanguard Institutional Index Fund), and individual stocks are derived from NAV and fund distribution data compiled by Commodity Systems, Inc. and downloaded from Yahoo! Finance. Parentheses contain t-statistics and the superscripts * and ${ }^{* *}$ indicate significance at the $5 \%$ and $1 \%$ levels, respectively.

FY 2003 FY 2004 FY 2003-2004

\begin{tabular}{|c|c|c|c|}
\hline $\begin{array}{l}\text { Alpha } \\
\left(\mathrm{t}_{0}\right) \\
\left(\mathrm{t}_{\mathrm{exp}}\right)\end{array}$ & $\begin{array}{l}-1.154 \text { b.p. } \\
(-2.80) \\
(-2.13)\end{array}$ & $\begin{array}{l}-0.862 \text { b.p. } \\
(-1.86) \\
(-1.33)\end{array}$ & $\begin{array}{l}-1.178 \text { b.p. } \\
(-3.59) \\
(-2.79)\end{array}$ \\
\hline S\&P 500 & $\begin{array}{c}0.861^{* *} \\
(57.80)\end{array}$ & $\begin{array}{c}0.893^{* *} \\
(52.60)\end{array}$ & $\begin{array}{c}0.880^{* *} \\
(77.26)\end{array}$ \\
\hline AIG & $\begin{array}{l}0.023^{* *} \\
(5.47)\end{array}$ & $\begin{array}{l}0.019^{* *} \\
(5.41)\end{array}$ & $\begin{array}{l}0.019^{* *} \\
(6.80)\end{array}$ \\
\hline Cardinal Health & $\begin{array}{l}0.011^{* *} \\
(4.57)\end{array}$ & $\begin{array}{l}0.005^{* *} \\
(2.64)\end{array}$ & $\begin{array}{l}0.008^{* *} \\
(5.04)\end{array}$ \\
\hline ChevronTexaco & $\begin{array}{l}0.010^{*} \\
(2.01)\end{array}$ & $\begin{array}{l}0.015^{* *} \\
(2.92)\end{array}$ & $\begin{array}{l}0.014^{* *} \\
(3.65)\end{array}$ \\
\hline Cisco & $\begin{array}{l}-0.008^{* *} \\
(-2.90)\end{array}$ & $\begin{array}{l}0.017^{* *} \\
(5.05)\end{array}$ & $\begin{array}{c}0.002 \\
(1.00)\end{array}$ \\
\hline Citigroup & $\begin{array}{l}0.028^{* *} \\
(5.28)\end{array}$ & $\begin{array}{l}0.024^{* *} \\
(3.36)\end{array}$ & $\begin{array}{l}0.025^{* *} \\
(5.54)\end{array}$ \\
\hline Clear Channel & $\begin{array}{l}0.025^{* *} \\
(8.63)\end{array}$ & $\begin{array}{l}0.017^{* *} \\
(4.33)\end{array}$ & $\begin{array}{l}0.021^{* *} \\
(8.35)\end{array}$ \\
\hline CVS & $\begin{array}{l}-0.000 \\
(-0.00)\end{array}$ & $\begin{array}{l}0.008 \\
(1.87)\end{array}$ & $\begin{array}{l}0.003 \\
(1.31)\end{array}$ \\
\hline Home Depot & $\begin{array}{l}0.012^{* *} \\
(3.92)\end{array}$ & $\begin{array}{l}0.010 \\
(1.88)\end{array}$ & $\begin{array}{l}0.013^{* *} \\
(4.29)\end{array}$ \\
\hline Merck & $\begin{array}{c}0.006 \\
(1.71)\end{array}$ & $\begin{array}{c}0.000 \\
(0.24)\end{array}$ & $\begin{array}{c}0.002 \\
(0.89)\end{array}$ \\
\hline Wal-Mart & $\begin{array}{c}0.008 \\
(1.76)\end{array}$ & $\begin{array}{c}-0.006 \\
(-0.99)\end{array}$ & $\begin{array}{c}-0.001 \\
(-0.23)\end{array}$ \\
\hline $\begin{array}{l}\text { Observations } \\
R^{2} \\
\text { Durbin-Watson }\end{array}$ & $\begin{array}{c}253 \\
0.9946 \\
2.1168\end{array}$ & $\begin{array}{c}251 \\
0.9897 \\
2.0159\end{array}$ & $\begin{array}{c}504 \\
0.9914 \\
2.0327\end{array}$ \\
\hline
\end{tabular}


statistical significance of the shortfall relative to the baseline regression in Table 4 . These results reiterate the observation that although some of Magellan's stock selections, particularly those in technology, hurt its performance, that damage was offset by Stansky's other picks.

In 2004, Robert Stansky's inopportune selection of stocks explains just under half of Magellan's underperformance that is not accounted for in its stated expenses, which is enough to reduce the t-statistics associated with alpha well below the traditional level of statistical significant. While poor stock selection may not account for Magellan's entire shortfall relative to the S\&P 500, there can be no mistaking that Stansky's predilection for the laggards within an industry had a measurable negative impact on the fund's performance.

Taking together, the lack of a statistical explanation for Magellan's underperformance in 2003 and the partial explanation for 2004 leave much unexplained by the regression that covers the two-year period. These results (also shown in Table 6) generate an alpha that is virtually identical to that for the industry regression. Extensive, if somewhat ill-advised, data mining (the results of which are not reported here) can only chip away one or two tenths of a basis point from an alpha that remains significant at the $1 \%$ level even when stated expenses are taken into account.

It is worth noted that all three stock-based regressions in Table 6 are slanted in favor of Robert Stansky's explanation of the fund's performance. Moreover, the regressions include additional companies, such as Home Depot, that are not mentioned in Magellan's annual report and yet had an unmistakably negative impact on the fund's fortunes, and restrict the positive influences on returns to those explicitly cited by Mr. Stansky.

\section{Post-Stansky Magellan}

Robert Stansky's stewardship of Magellan came to an abrupt end on Halloween of 2005. Fidelity announced his immediate departure from the firm and named Harry Lange, the celebrated manager of the Fidelity Capital Appreciation Fund, as the new head of Magellan.

Lange transformed Magellan into an altogether different fund from the moment he arrived. Figure 5 compares the monthly regression lines of Magellan's returns against those of the Vanguard index fund for October 2005 and November 2005. Magellan returns stayed close to the regression line throughout October (including October 31, Halloween) and then leapt off it on November 1 (All Saints' Day)_Harry Lange's first full day as its manager. It was as if Magellan had become human again.

The unaudited quarterly statement of Lange's holdings at the end of the year bore minimal resemblance to the Stansky's final semiannual statement just 3 months earlier. Magellan's taxable fund holders would get the bill for Lange's overhaul the following year for capital gains amounting to $20 \%$ of the fund's NAV. (Robert Stansky's low turnover caused Magellan to go for years without generating capital gains.) By the end of 2005, Lange managed to push Magellan 
$1.5 \%$ ahead of the S\&P 500 for that calendar year. Lange's outperformance carried into 2006; he was ahead of the index by $4.16 \%$ for the fiscal year ending March 31, 2006.

Harry Lange's arrival at Fidelity sent repercussions through the investment management industry. Lange's move set up a chain reaction of manager changes at Fidelity, with several managers moving up in the pecking order. Outside of Fidelity, portfolio managers appear to have gotten the word that shadow indexing can be a career-ending move. Across the board, monthly $R^{2}$ s for large-cap mutual funds plummeted in November 2005 and they remained lower for months.

Lange's magic touch, however, wore off quickly. For calendar year 2006, Lange would trail the S\&P 500 by $8.6 \%$ - underperformance more reminiscent of the darkest days of Vinik than of anything Stansky had done.
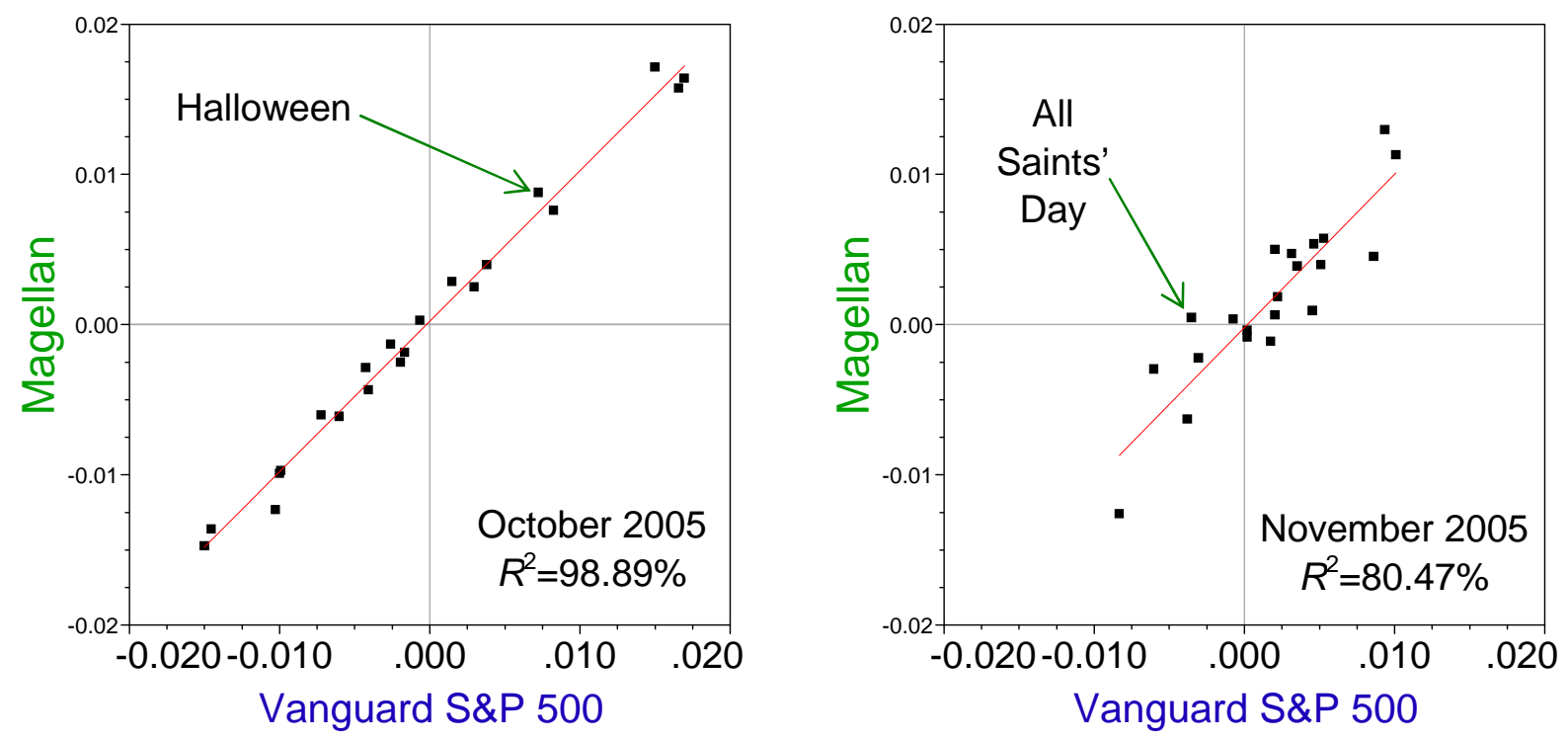

Figure 5. What A Difference a Day (and a Month) Makes.

Graphical representations of the regression lines used for the October and November 2004 data points in Figure 2. Robert Stansky's last day (Halloween, October 31) and Harry Lange's first full day (All Saints' Day, November 1) are indicated with arrows. 


\section{Where Did Two Billion Dollars Go?}

Magellan's daily shortfall of over 1 basis point relative to the S\&P 500 stock index during fiscal years 2003 and 2004 translated in a daily shortfall of \$6 million for Magellan's fund holders, or more than $\$ 3$ billion over the two-year period. Even after Magellan's stated expenses and Robert Stansky's bad bets captured by the preceding regression analysis for 2004 are considered, there is still approximately $\$ 2$ billion that must be accounted for in some manner.

There are only two places that the money could have gone. It could have left the fund as "hidden expenses" (including various transaction costs) or been lost inside in the fund as underperforming assets.

Standard techniques for estimating a mutual fund's transaction costs account for a trivial portion of Magellan's unexplained shortfall. For example, many researchers take a fund's stated turnover and multiply it by $0.50 \%$ to estimate transaction costs. For Magellan, this would amount to 6.5 basis points in 2003 and 3.0 basis points in 2004. Any reasonable expansion of these costs to account for fund withdrawals not included in the turnover number does little to explain Magellan's shortfall and these withdrawals were relatively small in 2003, the year with the largest unexplained loss. Losses associated with the possible poor timing of Magellan's limited trading must similarly amount to mere basis points per year. Finally, because Magellan's portfolio is dominated by liquid U.S. equities, there was essentially no mispricing in the fund's NAV for "market timers," whose activities developed into a full-blown financial scandal late in 2003, to exploit and drag down the fund's performance in the process.

In light of the fact that the mutual fund industry has seen more than its share of scandals in recent years, it is would be negligent to ignore the possibility that Magellan's shortfall might have its roots in actions of questionable legitimacy undertaken either by its management or that of the parent company. Fidelity's name has been absence from the major mutual fund scandals and it receives passing, though not stellar, grades for governance from Morningstar. A notable recent offense, for which the management company voluntarily remitted $\$ 42$ million to its mutual funds while awaiting resolution of the issue by the SEC, involved receiving excessive gifts from its outside brokers that included participation in a dwarf-tossing event in March of 2003 (Dow Jones Newswires, 2005).

Dwarves and related perquisites have nothing directly to do with Magellan's shortfall, but they reflect a culture at Fidelity that may be willing to test the limits of the law. Finance scholars have long suspected that mutual funds families can employ questionable means to "play favorites" as Gaspar, Massa, and Matos (2006) put it and transfer performance from one fund in a family to another. One particular way that Fidelity could have legally moved funds out of Magellan and into funds that it wished to promote was through its cross-trading system.

Ostensibly as a way to reduce transactions costs, Fidelity (like most large fund families) was granted waivers from the SEC and ERISA that allow it to trade securities internally among its funds before handing them off to its brokers, which included Fidelity's own brokerage subsidiary. Cross-trading systems can be legally used to transfer performance from one fund to 
another by using them as trading conduits that bear all the costs of trades, including their market impact. It is generally acknowledged, however, that the impact of such favoritism is likely to be small, and for a fund like Magellan with low turnover it would be miniscule. Indeed, if Magellan's reported turnover ratio is an accurate reflection of its overall trading activity (even taking the flow of assets out of the fund into account), there is no way that the costs associated with its transactions could amount to more than a trivial proportion of its shortfall relative to the S\&P 500. ${ }^{21}$

It should be noted that there is nothing in the pattern of Magellan's shortfall that suggests a systematic skimming of funds. The shortfall relative to the S\&P 500 takes the form of a slightly skewed normal distribution with its tails intact and with no tendency toward a lightening of returns on its good days. Based on publicly available information it is reasonable to conclude that Magellan's shortfall is almost entirely attributable to uncommonly poor stock selection by Robert Stansky that first surfaced in 2002 and persisted in varying degrees until his departure.

One has to wonder if some event or events that affected either Fidelity or Magellan within that timeframe and not just bad luck could have been responsible for the marked decline in $\mathrm{Mr}$. Stansky's stock-picking prowess.

It is no secret that Fidelity and other large, influential investors routinely received marketmoving information from the companies in which they held major stakes in advance of its public dissemination. Although this practice was long a grudgingly accepted aspect of the U.S. securities markets, outcry over how it unfairly favored institutions such as Fidelity at the expense of investors led the SEC to promulgate Regulate FD (Fair Disclosure) as a way to curtail it.

The impact of Regulation FD, which went into effect late in 2000, was relatively muted until something happened at the beginning of the fourth quarter of 2002. That was when Richard Jay Kogan, the CEO of pharmaceutical giant Schering-Plough, choose to visit Boston. While he was there, he met with four of his company's largest institutional shareholders and discussed the troubles facing his company. Fidelity was among the shareholders receiving this information and their dumping of Schering-Plough shares over the next three days helped slice $17 \%$ off its price. $^{22}$

Schering-Plough did not disclose its bad news to the public until after the market had closed on the third day of the stock plunge. The company announced on October 7, 2002 that the SEC had launched an inquiry into the suspicious behavior of its stock. ${ }^{23} \mathrm{Mr}$. Kogan resigned early in 2003 and would pay a civil penalty of $\$ 50,000$ to put the matter behind him while Schering-Plough

\footnotetext{
${ }^{21}$ One could, however, imagine a scheme where Magellan would serve as a front for other Fidelity funds by bearing the cost of their trades and replenish their positions quickly enough that they would not be considered as part of turnover. While Harry Lange's overnight transformation of the fund indicates that it would be possible for Magellan to perform such a role, it is not credible that Mr. Stansky or any portfolio manager would knowingly participate in such a scheme.

${ }^{22}$ See U.S. Securities and Exchange Commission (2003) for the details of these events and the regulatory response to them.

${ }^{23}$ Reuters (2002).
} 
faced a levy of $\$ 1,000,000$. Fidelity and its fellow Boston money managers had done nothing illegal in receiving the information, but the word was out to CEOs and other corporate executives to take Regulation FD seriously and specifically to avoid taking personal meetings with fund managers. Eric D. Roiter, Fidelity's Senior Vice President and General Counsel, had presciently stated in a July 31, 2000 comment on Regulation FD that gave Fidelity's reasons for opposing some of its key provisions, “...the proposed rule contains powerful disincentives for issuers and their management to be forthcoming in any discussions with individual investment managers and their analysts..."24

While it is difficult to ignore that the end of Fidelity's privileged access to information coincides with the onset of Stansky's difficulties at Magellan's, in the absence of details that might quantitatively demonstrate how Magellan benefited from this access prior to the enforcement of Regulation FD, such as the timing of its conversations with the managers of companies it held and the effect of those conversations on its holdings in them, there is no statistical way to link the two. And even if Robert Stansky's decline as a stock picker were connected with the enforcement of Regulation FD, this does not constitute an explanation of Magellan's subsequent underperformance, only of why it could no longer outperform the market.

Whatever was going on at Magellan, traditional statistical methods do essentially nothing to explain its shortfall in 2003. Perhaps some insight is to be had by looking beyond stocks, industries, and market factors toward other mutual funds.

Straightforward exploratory data analysis reveals some interesting things about Magellan and its brethren. Cluster analysis was performed on the 253 daily returns for Fiscal Year 2003 using not only the mutual funds in Tables 1 through 3, but also several funds that did not make the cut. The result of several versions of cluster analysis cast Magellan as a central member of the single tightest cluster of funds. This cluster includes Vanguard Institutional Index Fund, Fidelity Trend Fund, Fidelity Stock Selector Fund, and Fidelity Fund - in other words, the index and its closest shadows.

Of all the funds examined, Vanguard Institutional Index Fund captures the most variance in Magellan's returns. One way of viewing this is that not only is the S\&P 500 the best-fit index (in Morningstar's sense) for Magellan, an S\&P 500 index fund is its best-fit fund. If Fidelity had any distinctive style to its portfolio, then its best-fit fund would be another fund that tilted the same way. For example, the best-fit fund for Fidelity Contrafund is the American Funds Growth Fund of America. Funds outside of the Fidelity complex generally correlate most with funds of a similar style either inside or outside their family. Magellan, however, was not like another active fund, it was most like the index.

So, what can we make of this? Suppose that once Robert Stansky got settled in at Magellan he took his picks and fed them through a portfolio optimizer in an effort to create not only the "best" portfolio for the fund, but one that would have the best chance of beating the benchmark. Such a portfolio would not only include Stansky's picks, but also an even larger number of less-

\footnotetext{
${ }^{24}$ Roiter (2000).
} 
favored stocks included to diversify away the risk inherent in those selections. For example, Stansky's conscious choice of excluding utilities from Magellan's portfolio could lead the portfolio optimizer to place a premium on value-oriented stocks in other industries. These stocks could, in turn, skew the portfolio in ways that would require additional stocks to diversify away risks that they unintentionally added to the portfolio.

In the theoretically efficient market that underlies portfolio-optimization models, the prices of these diversifying stocks would be uninfluenced by Magellan's predilection for them. In a realworld environment where other funds were pursuing similar strategies, however, such stocks would be bid up in price. For a time, Magellan and its fellow optimizers would benefit from this overpricing, but in the long run market forces would bring prices back in line.

The long run may have been far off in the days of John Maynard Keynes, but by the beginning of the $21^{\text {st }}$ century it no longer was. The spectacular rise in hedge funds and their relentless hunt for alpha helped wring both inefficiency and volatility out of the securities markets.

Money managers who put misplaced faith in portfolio-optimization software might be sitting ducks for hedge funds. Stocks that trade at a premium solely because portfolio-optimization models select them for their diversification properties can be viewed as containing a "metafactor" that could appear indistinguishable from the statistical noise inherent in such models. In particular, regressions like those performed earlier in this article would fail to detect a metafactor's effect on fund performance. It would not be difficult for hedge funds or other sophisticated investors to develop a "metamodel" that would isolate such metafactors and profit from their mispricing. This approach has come to be known as "factor-model arbitrage" by some hedge fund managers. ${ }^{25}$

The pattern of returns exhibited by Magellan suggests that the fund may have fallen victim to some form of factor-model arbitrage. Recall that in his early days shadowing the S\&P 500 index, Robert Stansky first beat that benchmark, then struggled to match it, and finally fell inexplicably behind it. This is what could happen if, as described above, the models used to construct Magellan's portfolio created metafactors that were bid up in price before collapsing under speculative attack. Moreover, Robert Stansky might perceive a gap between model and reality that would make simple corrective action impossible, effectively freezing the fund into its positions. The only remaining option under such circumstances would be to restructure the fund completely. In the case of Stansky's Monster, that job fell to Harry Lange.

\section{Concluding Remarks}

Depending on how one views things, this article either shows how much or how little one can infer from the information that mutual funds provide to the public. While this information may be insufficient to determine definitively where all the money at Magellan went, it does provide considerable insight how Robert Stansky managed the fund and how this may have caused its

\footnotetext{
${ }^{25}$ The author engaged in private e-mail exchanges with hedge fund managers on factor-model arbitrage in February,
} 2004. 
spectacular underperformance. The statistical evidence is consistent with Mr. Stansky having employed portfolio-optimization techniques to play his fund directly off the S\&P 500. While many large-cap managers pursue similar strategies, Stansky's implementation of the strategy appears to have backfired on him in a way that makes it difficult to confirm Mr. Stansky's attribution of the Magellan's performance in its annual reports. Regardless of whether Mr. Stansky's fate was sealed by clever hedge fund managers, inaccessible CEOs, or an incredible streak of bad luck, this episode in investment management history contains lessons for portfolio managers and investors alike. 


\section{Appendix}

Robert Stansky's statement from Fidelity Magellan Fund's Annual Report for the period ending March 31, 2004 (Fidelity Management and Research Company, 2004):

Robust domestic economic growth and improved corporate profits helped fuel a broad-based rally in U.S. equity markets during the 12-month period ending March 31, 2004. The U.S. Commerce Department reported that the rate of economic growth - as represented by gross domestic product-was $8.2 \%$ in the third quarter of 2003 , followed by a solid $4.1 \%$ annualized rate in the fourth quarter. Not since 1984 had the economy grown as fast in back-to-back quarters. As for corporate profitability, the government said after-tax corporate profits rose by $7.6 \%$ in the fourth quarter of 2003 , following a $10.1 \%$ increase for the prior quarter. In response, major equity market benchmarks surged higher, most notably the Russell $2000^{\circledR}$ Index, a benchmark of small-cap stock performance, which returned $63.83 \%$ during the 12-month period. Elsewhere, the tech-heavy NASDAQ Composite ${ }^{\circledR}$ Index gained $49.38 \%$, the large-cap-oriented Standard \& Poor's $500^{\mathrm{SM}}$ Index rose $35.12 \%$, and the blue-chips' Dow Jones Industrial Average $^{\mathrm{SM}}$ advanced $32.39 \%$. As the period ended, geopolitical concerns, high energy prices and lackluster job growth combined to temper the market's advance.

Fidelity Magellan Fund posted a strong absolute return of $30.35 \%$ during the past year, but trailed both the S\&P 500 ${ }^{\circledR}$ and the Lipper ${ }^{\mathrm{SM}}$ Growth Funds Average, the latter of which returned $35.87 \%$. Underweighting the surging technology sector, including names such as Cisco Systems and Intel, was the primary reason for the fund's shortfall relative to the index. Weak results in health care also detracted from performance compared to the S\&P 500. Merck suffered when it announced that two drugs were being dropped out of Phase III clinical trials. Thus, its earnings estimates were cut and the stock fell quickly. Media play Viacom also detracted significantly as advertising activity among radio and local TV networks failed to accelerate. On the plus side, the fund's positioning in financials was generally positive. An emphasis on brokerage firms and other companies tied to the capital markets worked out well. Citigroup, the fund's largest holding at period end, was its best absolute contributor and second-best relative performer. Morgan Stanley and Goldman Sachs also boosted returns in this space. 
Robert Stansky's statement from Fidelity Magellan Fund's Annual Report for the period ending March 31, 2005 (Fidelity Management and Research Company, 2005):

Major U.S. equity benchmarks posted modest gains for the 12 months ending March 31, 2005. Stocks soared in the final quarter of 2004 in response to falling oil prices, a clear-cut conclusion to the presidential election, and positive economic and employment reports. The late-year surge accounted for nearly all of the 2004 calendar year's positive return. But the markets reversed course in the first quarter of 2005. Oil prices hit a record high of \$57 per barrel and gasoline prices did the same, as the average price of regular unleaded neared $\$ 2.11$ per gallon, according to the U.S. Energy Information Administration. Inflation concerns also took a toll, and the Federal Reserve Board hiked short-term interest rates seven times during the period. Despite the turmoil, most bellwether measures of equity market performance finished the period in the black. The Standard \& Poor's $500^{\mathrm{SM}}$ Index returned $6.69 \%$, the Dow Jones Industrial Average $^{\mathrm{SM}}$ gained $3.59 \%$ and the tech-heavy NASDAQ Composite ${ }^{\circledR}$ Index returned $0.82 \%$.

For the 12 months ending March 31, 2005, Fidelity Magellan Fund gained 3.14\%, trailing the S\&P $500^{\circledR}$ and the $4.26 \%$ return of the Lipper ${ }^{\mathrm{SM}}$ Growth Funds Average. The fund was hurt when regulatory issues weighed down the stock prices of several financial holdings I overweighted relative to the index, including insurance giant American International Group, Citigroup and mortgage provider Fannie Mae. The weak performance of large positions in the traditional media industry, particularly Viacom and Clear Channel Communications, also detracted from returns. On the positive end, overweighting the energy sector was the biggest plus compared to the S\&P 500. The sector's strong performance was driven by skyrocketing prices for oil and natural gas. Seven of the fund's top 20 contributors relative to the S\&P 500 were energy stocks, led by Burlington Resources and ChevronTexaco. Stock selection in food \& staples retailing also turned out well. Drugstore chain CVS was a top performer, while underweighting index component Wal-Mart paid off when the stock fell more than $15 \%$ during the past year. 


\section{Acknowledgements}

The author received helpful comments on an earlier draft of this paper from Mary O'Keeffe, Alex Castaldo, George Zachar, Kim Zussman, and an anonymous reader.

\section{References}

Allentuck, A. (2000). "Frankenfund Lives!” Globe and Mail, (September 23).

Bernstein, P. L. (1992). Capital Ideas. New York: Free Press.

Bogle, J. C. (1999). Common Sense on Mutual Funds. New York: John Wiley \& Sons.

Dow Jones Newswires. (2005). "Fidelity Dwarf Says He’s in Demand.” (November 4).

Fidelity Management and Research Company. (2002). "Fidelity Magellan Fund Annual Report for the year ending March 31, 2002." http://www.sec.gov/Archives/edgar/data/61397/000006139702000001/main.htm.

Fidelity Management and Research Company. (2003). "Fidelity Magellan Fund Annual Report March 31, 2003." http://www.sec.gov/Archives/edgar/data/61397/000006139703000001/main.htm.

Fidelity Management and Research Company. (2004). "Fidelity Magellan Fund Annual Report March 31, 2004."

http://www.sec.gov/Archives/edgar/data/61397/000006139704000004/main.htm.

Fidelity Management and Research Company. (2005). "Fidelity Magellan Fund Annual Report March 31, 2005." http://www.sec.gov/Archives/edgar/data/61397/000006139705000003/main.htm.

Fidelity Management and Research Company. (2006). "Fidelity Magellan Fund Annual Report March 31, 2006." http://www.sec.gov/Archives/edgar/data/61397/000006139706000002/magann.htm.

Gaspar, J. Massa M. and Matos P. (2006). "Favoritism in Mutual Fund Families? Evidence on Strategic Cross-Fund Subsidization," Journal of Finance 61(1), 73-104.

Kacperczyk, M. Sialm C. and Zheng L. (2005). "Unobserved Actions of Mutual Funds.” NBER Working Paper No. 11766.

Miller, R. (2007). "Measuring the True Cost of Active Management by Mutual Funds.” Journal of Investment Management 5(1).

Reuters. (2002). “Schering-Plough Reports and S.E.C. Inquiry.” New York Times. (October 8). 
Roiter, E. D. (2000). SEC Rule Comment: S7-31-99. http://www.sec.gov/rules/proposed/s73199/roiter1.htm

Sharpe, W. F. (1992). "Asset Allocation: Management Style and Performance Measurement." Journal of Portfolio Management 18(2), 7-19.

U.S. Securities and Exchange Commission. (2003). "Schering-Plough Corporation and Richard J. Kogan: Adminstative Proceeding File No. 34-48461." http://www.sec.gov/litigation/admin/34-48461.htm, (September 9).

Wyatt, E. (1997). “Magellan, A Year Later,” New York Times, (May 25). 